Article

\title{
Estrogen Receptor-Beta2 (ERß2)-Mutant p53-FOXM1 Axis: A Novel Driver of Proliferation, Chemoresistance, and Disease Progression in High Grade Serous Ovarian Cancer (HGSOC)
}

\author{
Chetan C. Oturkar ${ }^{1} \mathbb{D}$, Nishant Gandhi ${ }^{1}$, Pramod Rao ${ }^{1}$, Kevin H. Eng ${ }^{2} \mathbb{D}$, Austin Miller ${ }^{2} \mathbb{D}$, Prashant K. Singh ${ }^{3}$, \\ Emese Zsiros ${ }^{4}$, Kunle O. Odunsi ${ }^{4,+}$ and Gokul M. Das ${ }^{1, *(\mathbb{D}}$
}

1 Department of Pharmacology and Therapeutics, Roswell Park Comprehensive Cancer Center, Buffalo, NY 14263, USA; chetan.oturkar@roswellpark.org (C.C.O.); ngandhi@carisls.com (N.G.); pramodra@buffalo.edu (P.R.)

2 Department of Biostatistics \& Bioinformatics, Roswell Park Comprehensive Cancer Center, Buffalo, NY 14263, USA; kevin.eng@roswellpark.org (K.H.E.); austin.miller@roswellpark.org (A.M.)

3 Genomic Shared Resource, Roswell Park Comprehensive Cancer Center, Buffalo, NY 14263, USA; prashant.singh@roswellpark.org

4 Department of Gynecologic Oncology, Roswell Park Comprehensive Cancer Center, Buffalo, NY 14263, USA; emese.zsiros@roswellpark.org (E.Z.); odunsia@bsd.uchicago.edu (K.O.O.)

* Correspondence: gokul.das@roswellpark.org; Tel.: +1-716-845-8542

+ Current address: Department of Obstetrics \& Gynecology, University of Chicago Comprehensive Cancer Center, Chicago, IL 60637, USA.

Citation: Oturkar, C.C.; Gandhi, N.; Rao, P.; Eng, K.H.; Miller, A.;

Singh, P.K.; Zsiros, E.; Odunsi, K.O. Das, G.M. Estrogen Receptor-Beta2 (ERß2)-Mutant p53-FOXM1 Axis: A Novel Driver of Proliferation, Chemoresistance, and Disease Progression in High Grade Serous Ovarian Cancer (HGSOC). Cancers 2022, 14, 1120. https://doi.org/ $10.3390 /$ cancers 14051120

Academic Editor: Mandi Murph

Received: 31 December 2021 Accepted: 17 February 2022 Published: 22 February 2022

Publisher's Note: MDPI stays neutral with regard to jurisdictional claims in published maps and institutional affiliations.

Copyright: (C) 2022 by the authors. Licensee MDPI, Basel, Switzerland. This article is an open access article distributed under the terms and conditions of the Creative Commons Attribution (CC BY) license (https:// creativecommons.org/licenses/by/ $4.0 /)$.
Simple Summary: High grade serous ovarian cancer (HGSOC) is the most common and lethal subtype of ovarian cancer without effective therapeutic options. The high prevalence of mutations $(\sim 96 \%)$ in tumor suppressor p53 is a hallmark of HGSOC. Estrogen receptor-beta (ER $\beta)$ has been reported to be another important player in HGSOC, although the pro-versus anti-tumorigenic role of its different isoforms remains unclear. The aim of this study was to analyze the crosstalk between ER $\beta$ and mutant p53 and its impact on the pro-tumorigenic processes in HGSOC. Using the HGSOC cell line models and patient tumor tissue specimens, we demonstrated functional interaction between the ER $\beta 2$ isoform and mutant p53 and their ability to co-dependently increase FOXM1 gene transcription, decrease cell death, increase cell proliferation, and mediate resistance to carboplatin treatment. Furthermore, high levels of ER $\beta 2$ as well as FOXM1 correlated with worse patient survival. Collectively, our data suggest that the ER 32 -mutant p53-FOXM1 axis could be a novel therapeutic target for HGSOC.

Abstract: High grade serous ovarian cancer (HGSOC) is the most common and lethal subtype of epithelial ovarian cancer. Prevalence $(\sim 96 \%)$ of mutant p53 is a hallmark of HGSOC. Estrogen receptor-beta $(E R \beta)$ has been reported to be another important player in HGSOC, although the pro-versus anti-tumorigenic role of its different isoforms remains unsettled. However, whether there is functional interaction between ER $\beta$ and mutant p53 in HGSOC is unknown. ER $\beta 1$ and ER $\beta 2$ mRNA and protein analysis in HGSOC cell lines demonstrated that ER $\beta 2$ is the predominant isoform in HGSOC. Specificity of ER $\beta 2$ antibody was ascertained using cells depleted of ER $\beta 2$ and ER $\beta 1$ separately with isoform-specific siRNAs. ER $\beta 2$-mutant p53 interaction in cell lines was confirmed by co-immunoprecipitation and in situ proximity ligation assay (PLA). Expression levels of ER $\beta 2, E R \alpha$, p53, and FOXM1 proteins and ER $\beta 2$-mutant p53 interaction in patient tumors were determined by immunohistochemistry (IHC) and PLA, respectively. ER $\beta 2$ levels correlate positively with FOXM1 levels and negatively with progression-free survival (PFS) and overall survival (OS). Quantitative chromatin immunoprecipitation (qChIP) and mRNA expression analysis revealed that ER $\beta 2$ and mutant p53 co-dependently regulated FOXM1 gene transcription. The combination of ER $\beta 2$-specific siRNA and PRIMA-1 ${ }^{\text {MET }}$ that converts mutant p53 to wild type conformation increased apoptosis. Our work provides the first evidence for a novel ER $\beta 2$-mutant p53-FOXM1 axis that can be exploited for new therapeutic strategies against HGSOC. 
Keywords: high grade serous ovarian cancer; estrogen receptor-beta2; mutant p53; FOXM1; therapeutic resistance; carboplatin; patient tumors; proximity ligation assay; apoptosis; cell proliferation

\section{Introduction}

Epithelial ovarian cancer (EOC) is a leading cause of fatality among gynecological cancers [1]. It represents a group of complex and heterogeneous diseases of which highgrade serous ovarian cancer (HGSOC) is the most aggressive and accounts for more than $60 \%$ of EOCs and over $70 \%$ of all deaths due to ovarian cancer [2]. HGSOC is commonly diagnosed at an advanced stage [3]. Peritoneal metastasis is the main reason for the poor prognosis of therapy-resistant HGSOC. Recent studies have indicated that HGSOC may have dual origins from both fallopian tube and ovarian surface epithelium [4,5]. HGSOCs are typically high-grade, genetically unstable, and harbor p53 (TP53) mutations [2,6]. While wild type p53 is expressed in low-grade serous carcinomas (LGSOC), mutant or null alleles of p53 are universally ( $96 \%)$ present in HGSOC [2]. A study based on the International Agency for Cancer Research (IARC) p53 database reported that over $70 \%$ of p53 mutations were missense mutations (which causes amino-acid substitution) with smaller contributions from frameshift, nonsense, and splice mutations [7]. Individual hotspot mutations could have a different impact on HGSOC patient outcomes [8]. Mutant p53 was reported to promote epithelial ovarian cancer by regulating tumor differentiation, metastasis, and responsiveness to steroid hormones [9]. Based on TCGA analyses, HGSOC treated with standard platinum- and taxane-based chemotherapy had higher rates of resistance in tumors with oncomorphic p53 mutations with predicted gain-of-function (GOF) effects in the absence of the wild type TP53 allele [10-12]. Importantly, while many driver mutations evolved in response to therapeutic intervention contributing to resistance, p53 mutations are unchanged during the course of the disease $[7,13,14]$.

Various research groups have reported on the roles of estrogen signaling in ovarian cancer [15]. Estrogen action is mediated by two receptors: estrogen receptor-alpha $(E R \alpha / E S R 1)$ and estrogen receptor-beta (ER $\beta / E S R 2)$, transcriptional regulators belonging to the large family of nuclear receptors. Although expression of ER $\alpha$ in HGSOC has been reported [16-18] and was shown to be positively correlated with lymphovascular space invasion (LVSI), a prognostic indicator of poor survival [19], a large study conducted by the Ovarian Tumor Tissue Analysis consortium in 1742 HGSOC cases showed that ER $\alpha$ was not associated with improved HGSOC survival [18]. Although there are various reports on the role of ER $\beta$ in HGSOC, they have been inconsistent $[20,21]$. While some studies have reported ER $\beta$ to have anti-proliferative effects in tumor cell lines and cell line-derived xenografts $[20,22-26]$ and to be associated with longer progression-free survival (PFS) and/or overall survival (OS) of patients [27-29], others have reported pro-tumorigenic effects $[20,30,31]$. Differences in cell lines, patient cohorts, antibodies, immunohistochemistry (IHC), and protocols used in the studies could have contributed to the inconsistencies besides the differences in the isoforms of ER $\beta$ that were analyzed. Estrogen signaling interacts with various proteins and signaling pathways. Although the unfavorable prognostic role of ER $\beta 2$ in HGSCO [20] and mitochondrial ER $\beta 2$ driving antiapoptotic pathways have been reported, interaction between ER $\beta 2$ and p53 signaling remains unknown. Because of the absence of wild type p53, a transcriptional repressor of FOXM1 [32,33], the latter is highly expressed in HGSOC and is a major driver of these cancers [2,34]. Although interaction between ER $\beta$ and p53 has been reported in other cancers [35-37], whether they interact in HGSOC and drive oncogenesis via FOXM1 remained unknown until we showed that such interaction with functional consequences occurs in HGSOC [38]. Identifying and understanding molecular mechanisms of signaling pathways that crosstalk to drive ovarian cancer and contribute to therapeutic resistance is necessary to gain insight to develop novel therapeutic strategies. Using multiple HGSOC cell lines authenticated by genomic 
profiling [39] and in-house HGSOC patient tumor tissues, we addressed ER $\beta 2$-p53 crosstalk and its functional implications in tumor progression and therapeutic resistance.

\section{Materials and Methods}

\subsection{Cell Culture and Reagents}

OVCAR3 (HGSOC cell line expressing mutant p53 R248Q), A2780 (none-serous ovarian cancer cell line expresses expressing wild type p53), KURAMOCHI (HGSOC cell line expressing mutant p53 D281Y) and OV-90 (HGSOC cell line expressing mutant p53 S215R), and MDA-MB-231 (TNBC cell line expressing mutant p53 R280K) were cultured in Dulbecco's Modified Eagle's medium (DMEM) (Corning, Corning, NY, USA, Cat \#10-013CM) supplemented with 10\% fetal bovine serum (FBS) (GIBCO/Thermo Fisher, Waltham, MA, USA, Cat \#20937-028), penicillin and streptomycin (50 g/mL). All cell lines were grown at $37^{\circ} \mathrm{C}$, under $5 \% \mathrm{CO}_{2}$, in a humidified incubator. FT282-C11 cell line (immortalized/untransformed fallopian tube fimbrial epithelial cells expressing mutant p53 R175H) was maintained in DMEM/F12 without L-Glutamine (Invitrogen/Thermo Fisher, Waltham, MA, USA, Cat \#21331-020) medium containing 10\% Horse Serum (Gibco/Thermo Fisher, Waltham, MA, USA, Cat \#16050130). FT282-C11 cells were provided by Dr. Michael Higgins (Roswell Park Comprehensive Cancer Center/RPCCC). Kuramochi cells were provided by Dr. Adam Karpf (University of Nebraska, USA). OV-90 cells were purchased from ATCC. All cell lines were authenticated by short tandem repeat (STR) analysis. Carboplatin (Cat \#41575-94-4, Millipore Sigma-Calbiochem, St. Louis, MO, USA) was provided by Dr. Xinjiang Wang (RPCCC). PRIMA-1 ${ }^{\text {MET }}$ (Cat \#3710) was purchased from TOCRIS Bio-Techne Corporation, Minneapolis, MN, USA. DPN Cat \#1494), $\beta$-Estradiol (Cat \#E2758, Sigma-Aldrich, St. Louis, MO, USA), PHTPP (Cat \#2662), and 4-Hyrdoxy tamoxifen (Cat \#3421) from TOCRIS, Bioscience, Bristol, UK).

\section{2. siRNAs and Transfection}

Cells were seeded and maintained in their respective media for $24 \mathrm{~h}$. Non-specific stealth control siRNNA (Invitrogen/Thermo Fisher, Waltham, MA, USA, Cat \#12935-300), or siRNAs against ER $\beta 1$ and ER $\beta 2$ sequences were transiently transfected using Lipofectamine 3000 (Thermo Fisher Scientific, Waltham, MA, USA, Cat \#13000015), as per the manufacturer's protocol. Cells were transfected with a final concentration of $120 \mathrm{nM}$ stealth control siRNA (si-NS), si-ER $\beta 1$ or si-ER 32 for 48 h or $50 \mathrm{nM}$ p53 siRNA for $24 \mathrm{~h}$. Post transfection, cells were harvested for downstream analysis. Sequence information of siRNAs is provided in Table S1.

\subsection{RNA Isolation and Quantitative Real Time PCR (RT-qPCR) Assays}

Total cellular RNA was isolated using TRizol reagent (Invitrogen, Waltham, MA, USA, Cat \#15596026) as per the manufacturer's protocol; RNA Integrity and yield was checked on a $1.5 \%$ agarose gel and quantified using a Nanodrop 8000 spectrophotometer. Isolated RNA treated with DNAse I, amplification grade I (Invitrogen/Thermo Fisher, Waltham, MA, USA) was used for cDNA synthesis. The first strand cDNA pool was synthesized using $1 \mu \mathrm{g}$ of total RNA and BioRad's iScript ${ }^{\mathrm{TM}}$ CDNA synthesis kit (BioRad, Hercules, CA, USA), Cat \#170-8891) in a $20 \mu \mathrm{L}$ reaction volume. Quantitative real time (qRT-qPCR) was performed using an iTaq Universal SYBR Green supermix (BioRad, Hercules, CA, USA, 1725121) in a $10 \mu \mathrm{L}$ reaction in Applied Biosystem's ABI Prism 7300 Real time PCR machine: $50{ }^{\circ} \mathrm{C}$ for $15 \mathrm{~s}$ ( 1 cycle); $95{ }^{\circ} \mathrm{C}$ for $10 \mathrm{~min}\left(1\right.$ cycle); $95^{\circ} \mathrm{C}$ for $15 \mathrm{~s}$, followed by $60{ }^{\circ} \mathrm{C}$ for $45 \mathrm{~s}$ (40 cycles). Dissociation curves were used to confirm the detection of a single amplicon. Data acquisition and analysis was carried out by ABI's 7300 system sequence detection software V1.4. The relative target levels were determined by the $\Delta \Delta C T$ method using $\beta$-actin mRNA as reference gene endogenous controls. All experimental and control groups were performed in biological and technical triplicates. Details of PCR primers are shown in Table S1. 


\subsection{Immunoblotting}

For immunoblotting, cells were scraped in ice cold 1xPBS, followed by centrifugation at $5000 \mathrm{rpm}$ for $5 \mathrm{~min}$ at $4{ }^{\circ} \mathrm{C}$. The cell pellet was lysed in RIPA buffer and quantification of protein was performed using Bradford reagent (BioRad, USA Cat \#5000006) as per the manufacturer's protocol. The protein lysates were subjected to SDS-PAGE, followed by immunoblotting. The details of the antibodies along with dilutions used are provided in Table S2. The specificity of the ER $\beta 2$ antibody was ascertained by knocking down ER $\beta 2$ with specific siRNA and the overexpression of the ER $\beta 2$ expression plasmid (see Figure S3).

\subsection{Co-Immunoprecipitation (Co-IP) Assay}

OVCAR3 cells were harvested and lysed in an ice cold RIPA lysis buffer (50 mM Tris- $\mathrm{HCl} \mathrm{pH}$ 8.0, 1\% NP-40, $150 \mathrm{mM} \mathrm{NaCl}$, 0.5\% deoxycholate, 0.1\% SDS, $5 \mathrm{mM}$ EDTA) and EDTA-free "Roche cOmplete" protease inhibitor cocktail (Millipore Sigma, St. Louis, MO, USA, Cat \#11873580001) for $30 \mathrm{~min}$. Cell lysates were further centrifuged at 15,000 rpm for $10 \mathrm{~min}$ at $4{ }^{\circ} \mathrm{C}$ and then pre-cleared with protein $\mathrm{G}$ agarose (Life Technologies/Thermo Fisher, Waltham, MA, USA, Cat \#15920010) for $1 \mathrm{~h}$ at $4{ }^{\circ} \mathrm{C}$. Approximately $2.5 \mathrm{mg}$ of precleared lysate was incubated with $5 \mathrm{mg}$ of ER $\beta 2$ or IgG specific antibody overnight. After $24 \mathrm{~h}$, immunogen-antibody complexes were incubated with freshly prepared a lysis buffer saturated with protein $\mathrm{G}$ agarose beads at $4{ }^{\circ} \mathrm{C}$. After $3 \mathrm{~h}$, the beads were then washed three times with wash buffer (RIPA buffer without SDS and Triton). Protein complexes were eluted in $2 \times$ sample buffer (100 mM Tris, pH 6.8; $4 \%$ SDS; $20 \%$ glycerol; $10 \%$ 2-mercaptoethanol; $0.2 \%$ bromophenol blue) and processed for immunoblotting. ER $\beta 2$ and IgG antibodies are detailed in Table S2. The specificity of the ER $\beta 2$ antibody was ascertained using cells where ER $\beta 2$ and ER $\beta 1$ were depleted separately with isoform-specific siRNAs.

\subsection{Chromatin Immunoprecipitation (ChIP) Assay}

OVCAR3 $\left(1 \times 10^{7}\right)$ cells were washed with ice cold 1XPBS and incubated for crosslinking with 1\% formaldehyde solution (Sigma, St Louis, MO, USA, Cat \#F1635). The crosslinking reaction was stopped by adding 0.125 M Glycine (VWR, Atlanta, GA, USA, Cat \# 56-40-6). Cells were washed three times and scrapped in Szak's RIPA buffer (150 mM NaCl, $1.0 \%$ NP-40, 0.5\% deoxycholate, 0.1\% SDS, $50 \mathrm{mM}$ Tris- $\mathrm{HCl} \mathrm{pH} 8,5 \mathrm{mM}$ EDTA and $0.5 \mathrm{mM}$ PMSF free Complete protease inhibitor cocktail (Millipore Sigma, St. Louis, MO, USA, Cat \#11873580001). After incubating the cell pellet with the lysis buffer for $10 \mathrm{~min}$ on ice, the cell lysate was sonicated using Diagenode Biorupter Sonicator (Diagenode, NJ, USA, Cat \#B01010002) at the setting "HIGH" with $30 \mathrm{sec}$ ON/30 s OFF phases for 5-min interval cycle. The sample was sonicated to obtain optimum smear of approximately 100-500 bps. Approximately $1 \mathrm{~mL}$ cell lysate was incubated with ER $\beta 2$ specific or IgG (negative control) specific antibody overnight on rotor at $4{ }^{\circ} \mathrm{C}$, followed by further incubation at $4{ }^{\circ} \mathrm{C}$ for $2 \mathrm{~h}$ after addition of $20 \mu \mathrm{L}$ Pierce Protein A/G magnetic beads (Thermo Fisher, Waltham, MA, USA, Cat \#88802). Antibody-chromatin complex linked magnetic beads were separated using a magnetic rack and washed ( 5 min each on rocker) with series of buffers (low salt immune complex, high salt immune complex wash buffer, $\mathrm{LiCl}$ immune complex wash buffer, $2 \times$ TE Buffer). After the final wash, $250 \mathrm{~mL}$ of $1.5 \times$ Talianidis elution buffer (70 mM Tris- $\mathrm{HCl}$ pH 8, 1 mM EDTA and 1.5\% SDS) was used to separate immunocomplex from beads. Eluted immunocomplex was incubated further for $10 \mathrm{~min}$ at $65^{\circ} \mathrm{C}$, followed by boiling at $95{ }^{\circ} \mathrm{C}$ for a few seconds. Reverse crosslinking was performed by adding $13 \mathrm{~mL}$ of $4 \mathrm{M} \mathrm{NaCl}$ to each sample and further incubation at $65{ }^{\circ} \mathrm{C}$ for $5 \mathrm{~h}$. After $24 \mathrm{~h}$, sample was incubated with $2 \mathrm{~mL}$ of $2 \mathrm{mg} / \mathrm{mL}$ Proteinase K (New England Biolabs, Ipswich, MA, USA, Cat \#P8102S) at $45^{\circ} \mathrm{C}$ for $1 \mathrm{~h}$. DNA was precipitated using Phenol-chloroform extraction followed by ethanol precipitation. Purified DNA was resuspended in $50 \mathrm{~mL}$ $1 \times \mathrm{E}$ buffer and analyzed with quantitative real-time PCR (qRT-PCR) using nonspecific primers (region $-2792 \mathrm{bp}$ to $-2965 \mathrm{bp}$ ) and estrogen receptor response element (ERE) site 
primers ( $-2565 \mathrm{bp}$ to $-2965 \mathrm{bp}$ ) on the FOXM1 gene promoter. Sequence details of the ChIP primers are provided in the Table S1.

\subsection{Flow Cytometry Analysis}

Cells were transfected with siRNA for $48 \mathrm{~h}$, followed by treatment with carboplatin $(4 \mu \mathrm{M})$ for $24 \mathrm{~h}$. Post treatment, cells were washed with PBS followed by Annexin V (FITC) and PI staining as per manufacturer protocol (BD Bioscience, Franklin Lakes, NJ, USA, Cat \#556570). Stained cells were analyzed by FACS Calibur flow cytometer and apoptotic data was plotted using Winlist 8.0 software. The assay was performed in triplicates and statistical tests were computed using the ANOVA test.

\subsection{Colony Formation Assay}

$48 \mathrm{~h}$ post siRNA transfection and drug treatment, approximately 2000 cells $/ \mathrm{cm}^{2}$ were seeded and allowed to grow for 8-10 days. The cells were fixed with $10 \%$ formaldehyde solution for $15 \mathrm{~min}$ at room temperature. Subsequently, cells were stained with $0.1 \%$ crystal violet solution for $15 \mathrm{~min}$ at room temperature. Unabsorbed crystal violet dye was washed away by submerging the plate several times in running water. Plates were completely air dried at ambient temperature for several hours and photographed. For quantitation purposes, the absorbed dye, which is proportional to the cell mass, was extracted with $10 \%$ acetic acid solution. $100 \mu \mathrm{L}$ of extract per sample was loaded into 96-well plates, and the absorbance at $595 \mathrm{~nm}$ was measured using a Synergy 2 (BioTek Winooski, VT, USA) plate reader.

\subsection{Immunohistochemistry (IHC) on Patient Tissue Microarray (TMA)}

\subsubsection{Patient Characteristics and Tissue Procurement}

Primary and metastatic tumors from 44 patients were used to create the TMA. All patients had high grade serous ovarian or primary peritoneal cancer. The median age of the patients was 63 years (range 39-88). Ninety-eight percent of the patients were Caucasian and $2 \%$ were American Indian. All patients underwent primary debulking surgery without receiving neoadjuvant chemotherapy. Tumor stage distribution was stage $1 \mathrm{~A}(2 \%)$, stage $2 \mathrm{~B}(2 \%)$, stage $3(60 \%)$, stage $4(27 \%)$, and undefined $(9 \%)$.

All activities of tissue procurement are directed and recorded by the Laboratory Information Management System (LIMS) at RPCCC. LIMS associates data to a sample family, including where/how the specimen was obtained, what precisely the sample is, and what the quality of that sample is. The system also tracks the life history of a biospecimen throughout its procurement, storage and distribution along with all associated core laboratory data.

\subsubsection{TMA Construction}

Two ovarian TMAs (GynCa10 and GynCa11) constructed from primary tumors and their counterpart peritoneal metastatic tumor tissues were made available by the RPCCC Pathology Network Shared Resource (PNSR). Three 1-mm tissue cores from each formalinfixed paraffin embedded (FFPE) donor blocks were precisely arrayed onto a new recipient paraffin block that included tumor specimens and controls. Eligible patients had surgeries performed between 1995 and 2008 at RPCCC, Buffalo, NY. Specimens for controls within the TMA consisted of multiple cores of normal tissue from 10 different organs including heart, colon, kidney, adrenal, ovary, myometrium, brain, thyroid, lung, and prostate, thereby representing more than $20 \%$ of all the cores in a TMA.

The usage of TMAs with patient tumor tissues was approved (BDR 060615) by the Institutional Review Board (IRB) for all ethical compliances consistent with federal, state, and local requirements. All tumor tissue specimens were obtained in de-identified format. 


\subsubsection{Antigen Retrieval}

FFPE sections from GynCa10 and GynCa11 TMAs together contained 132 tumor tissues, of which 44 were primary tumor tissues, along with their respective peritoneal metastatic tumor tissues; 44 additional cases were primary tumors, and another 10 were metastatic tumors. Formalin-fixed paraffin sections of these TMAs were cut at $4 \mu \mathrm{M}$, placed on charged slides, and dried at $60^{\circ} \mathrm{C}$ for one hour. Slides were cooled to room temperature and added to the Dako Omnis autostainer, where they were deparaffinized with Clearify (American Mastertech, McKinney, TX, USA, Cat \# Caclegal) and rinsed in water. Flex TRS High pH (Dako, Carpinteria, CA, USA, Cat \# GV804) was used for target retrieval for 30 min for FOXM1 and p53. TRS Low pH (Dako, cat\# GV805,) was used for target retrieval for ER $\beta 2$. Slides were incubated with FOXM1 antibody (sc-502, Santa Cruz Biotechnology, Dallas, TX, USA) or p53 antibody (Santa Cruz Biotechnology, Dallas, TX, USA, Cat \# sc-126) for $30 \mathrm{~min}$ at 1:50 dilution, followed by Flex HRP polymer (Dako, Cat \# DM843) which was applied for $30 \mathrm{~min}$. For staining slides for ER $\beta 2$, the ER $\beta 2$ antibody (BioRad, Hercules, CA, USA, Cat \# MCA2279,) was applied at 1:200 dilution for $20 \mathrm{~min}$ followed by Flex HRP polymer for $20 \mathrm{~min}$. DAB (Diaminobenzidine) was applied (Dako, Cat \# K3468) for 5 min for visualization. Slides were counterstained with Hematoxylin for $8 \mathrm{~min}$ and then put into water. After removing slides from the Omnis, they were dehydrated, cleared, and coverslips were mounted on to them.

\subsubsection{Quantitative Scoring of Nuclear ER $\beta 2$ and TP53 and FOXM1 Immunohistochemistry Signals}

TMA slides were digitally scanned using an Aperio Scanscope (Aperio Technologies, Inc., Vista, CA, USA) with $20 \times$ bright-field microscopy. These images were accessible using Spectrum (Aperio Technologies, Inc., Vista, CA, USA), a web-based digital pathology information management system.

Once the slides were scanned, the Aperio ImageScope version 12.4.3.7009 (Aperio Technologies, Inc., Vista, CA, USA) was used to view images for analysis. An annotation layer was created for each core of interest in the TMA for targeting cells of interest for analysis. Regions were identified and annotated to appropriately represent the heterogeneity of staining of each TMA core and to reduce irrelevant regions from image analysis calculations.

The Aperio platform was used to develop quantitative image analysis algorithms for the quantification of slides. Briefly, these algorithms use color de-convolution to separate diaminobenzidine (DAB) from the haematoxylin counterstain, thereby providing stain separation. Each algorithm is tailored to fine tune the cell feature detection using cellular, nuclear, and stain parameters, creating a specific macro based on the cell compartment location of each target protein. The algorithm was adjusted for each antibody target and tissue combination to optimize results.

The Cytoplasmic algorithm was used to create a macro for both ER $\beta 2$ and FOXM1. The macro analyzes DAB staining intensity and the percentage of cells containing the stain within the cytoplasm compartment. The analysis results provide the total number of cells, percentage per scoring class, and $\mathrm{H}$ - Score. The $\mathrm{H}$-score is a weighted index score derived from the average intensity of the staining of the cytoplasm according to the threshold intervals set in the algorithm. This score equals $=1 \times(\% 1+)+2 \times(\% 2+)+3 \times(\% 3+)$, with the score ranging between 0 and 300 , where 300 represents $100 \%$ of cells being $3+$.

The Nuclear algorithm was used to create a macro for both ER $\beta 2$ and p53. The macro detects the positive (DAB) nuclear staining for the individual tumor cells and quantifies their staining intensity. The analysis results provide the total number of detected cells, the percentage of cells per scoring class $(0,1+, 2+$ and $3+)$ and the percentage of positively stained cells along with each sample's average staining intensity of the positive nuclei as a score of $0,1+, 2+$ and $3+$. The $\mathrm{H}$-score was manually generated based on the same formula above. 


\subsection{Proximity Ligation Assay (PLA)}

\subsubsection{Fluorescence-Based PLA}

In situ PLA in cultured cells was carried out using the Duolink II reagent kit (MilliporeSigma, St Louis, MO, USA cat\# DUO92008) and supplier's protocol. Briefly, 10,000 cells were seeded on $12 \mathrm{~mm}$ coverslips (Thermo Fisher Scientific, Grand Island, NY, USA) in 24-well plates. After 12-24 h, cells were fixed with freshly prepared $2 \%$ paraformaldehyde (Millipore-Sigma, St Louis, MO, USA cat\#P6148) solution in PBS, pH 7.4 at room temperature for $20 \mathrm{~min}$. Subsequently, the coverslips were washed twice with $1 \mathrm{~mL}$ of PBS, blocked and permeabilized with a solution containing $2 \%$ BSA and $0.1 \%$ Triton-X-100 in PBS, $\mathrm{pH} 7.4$, for $1 \mathrm{~h}$ at room temperature, followed by nuclear permeabilization using a buffer containing 1\% BSA and 0.1\% NP40 in PBS, pH 7.4, for $15 \mathrm{~min}$ at room temperature. Mouse and rabbit primary antibodies were diluted appropriately in antibody dilution buffer (supplied in the kit) and were applied to the coverslips in an open droplet manner and incubated at room temperature for $1 \mathrm{~h}$ in a humidified chamber. The remainder of the protocol, which included secondary probe hybridization, ligation, and amplification, were carried out as per the manufacturer's instructions. Coverslips were mounted with the supplied mounting media containing DAPI. Photographs were taken with an AXIOSKOP (Carl Zeiss, Jena, Germany) fluorescent microscope fitted with a Hamamatsu 3CCD digital camera and ImagePro Plus Software. PLA signals were quantitated by ImageJ software (NIH, Bethesda, MD, USA) or by manual counting.

\subsubsection{Bright-Field PLA}

FFPE ovarian TMAs (GynCa10 and GynCa11) were deparaffinized in xylene for 3 min and hydrated through an ethanol gradient ( $3 \mathrm{~min}$ in $100 \%, 3 \mathrm{~min}$ in $70 \%$ ). After hydration, TMAs were washed twice with tris-buffered saline with Tween 20 (TBST) followed by antigen retrieval using antigen retrieval buffer (EnVision FLEX Target Retrieval Solution, High pH 50× (Dako Omnis, Cat \# GV804) in a steamer at $100{ }^{\circ} \mathrm{C}$ for $1 \mathrm{~h}$. TMA slides were cooled at room temperature and further quenched by Duolink hydrogen peroxide (Millipore-Sigma, St Louis, MO, USA, Cat \# DUO82054) for $10 \mathrm{~min}$ followed by blocking by Duolink blocking solution (Millipore-Sigma, Cat \# DUO82007) for 5 min. Primary antibodies of ER $\beta$ (Santa Cruz Biotechnology, Dallas, TX, USA, Cat \# 14C8) (1:100 dilution in antibody dilution buffer) and FL393 (Santa Cruz Biotechnology, Cat \# DO1(1:100 dilution in antibody dilution buffer) were applied onto each TMA (50 $\mu \mathrm{L})$ and incubated further for $1 \mathrm{~h}$ in a humidified chamber. Following the primary antibody incubation, mouse PLUS and rabbit MINUS secondary PLA antibodies were diluted appropriately in an antibody dilution buffer and were applied to the TMA $(50 \mu \mathrm{L})$ and incubated for $1 \mathrm{~h}$ in a humidified chamber. The ligation and amplification reactions were carried out on all slides as described by the manufacturer (Millipore-Sigma, St. Louis, USA, Cat \# DUO92012A). After amplification, TMAs were incubated with a Horseradish peroxidase (HRP)-labeled hybridization probe for $1 \mathrm{~h}$ in a humidity chamber at $37^{\circ} \mathrm{C}$ followed by incubation with substates (A, B, C and D) as per the manufacturer's protocol (Millipore-Sigma, St. Louis, USA, Cat \# DUO92012B). Following two washes with distilled water, TMAs were then counterstained for $1 \mathrm{~min}$ in the Duolink nuclear stain (Millipore-Sigma, St. Louis, USA, Cat \# DUO82059). TMA sections were dehydrated $(2 \times 3 \mathrm{~min}$ in 95\% ethanol; $2 \times 1 \mathrm{~min}$ in $100 \%$ ethanol) and transferred to xylene $(3 \mathrm{~min})$ and cover slips were mounted using mounting media (Thermo Fisher Scientific, Grand Island, NY, USA, Cat \# 23425401). After overnight incubation, TMAs were scanned by Leica Aperio ScanScope XT and images were captured using the Aperio Spectrum Digital Slide System. ERß2-p53 interaction signal dots per 300 nuclei were manually counted in all tumor tissues on the TMAs.

\subsection{Statistical Analysis}

For general comparison, triplicate data sets were analyzed by Student's $t$-test and oneway ANOVA with multiple comparisons using GraphPad Prism 9 software (San Diego, CA, USA). Statistical analyses for generating Kaplan-Meier survival curves (Figure 1D,E) were 
performed in R4.0.3; all tests were two-sided and $p$-values less than 0.05 were considered significant. Survival analyses used Contal and O'Quigley's method [40] to select a cut point. Based on the H-Scores from IHC, the relationship between ER $\beta 2$ and FOXM1 or p53 in primary or metastatic tumors were analyzed using Spearman correlation methods, including 95\% confidence bands for the correlation coefficient estimates (Figure 2B). The $p$ values address the null hypothesis of no correlation between the two markers in each plot. The $p$ values on the plot are unadjusted.

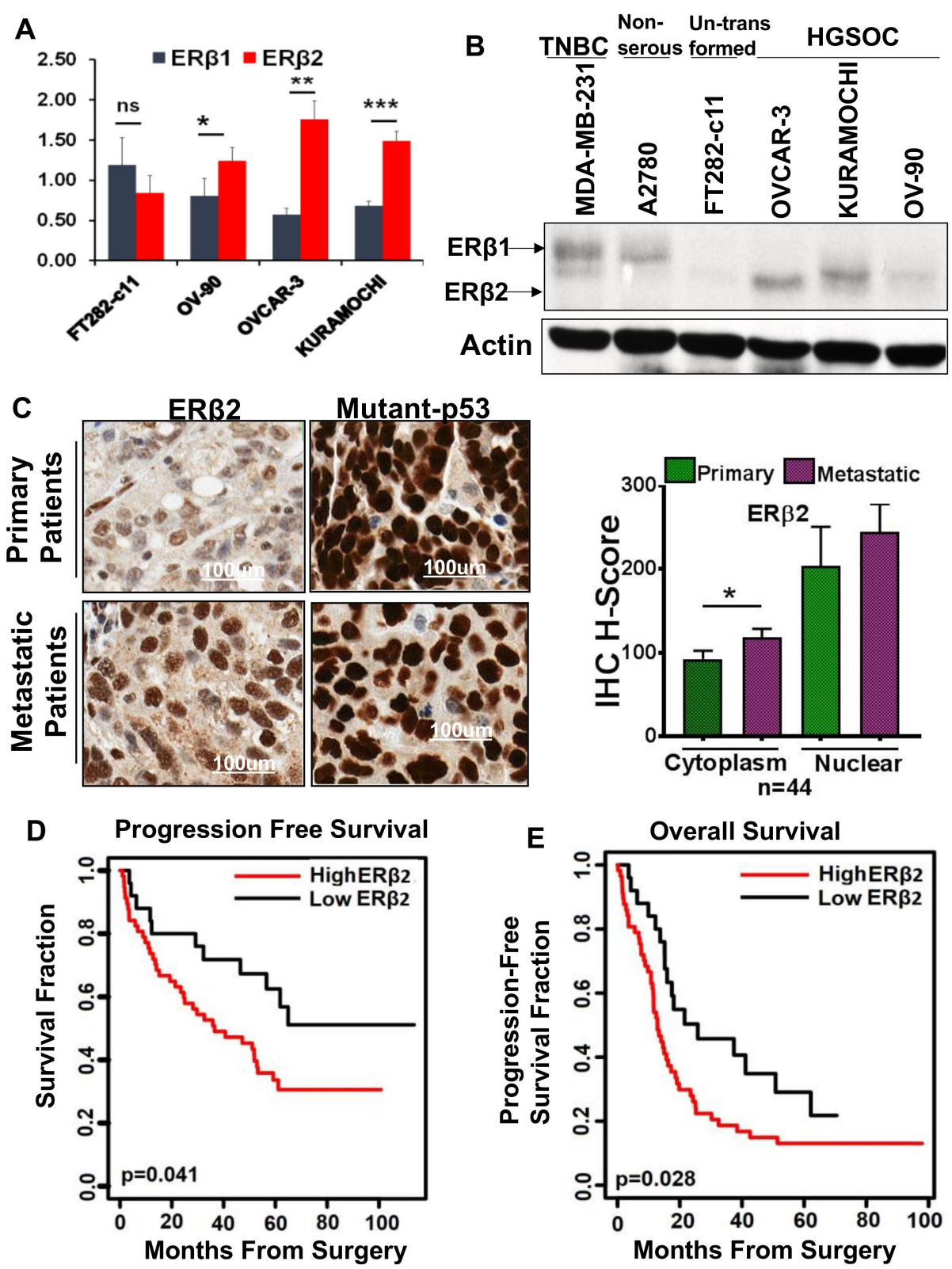

Figure 1. High ERß2 expression is associated with tumor progression in HGSOC. (A) Total mRNA was isolated from FT282-c11 (untransformed fallopian tube cells), OVCAR3, KURAMOCHI, and OV-90 (HGSOC) using the Trizol method. The elative level of mRNA expressions was determined using quantitative real time PCR (qRT-PCR). Three independent experimental replicates were used for statistical analysis. The error bar represents $\mathrm{SD}$ and $p$ values were analyzed using unpaired student $t$ test. ns $=$ non-significant, ${ }^{*}=<0.005,{ }^{* *}=0.001$, and ${ }^{* * *}=<0.0001$. (B) FT282-C11 (untransformed), OV90, OVCAR3, and KURAMOCHI (HGSOC cell lines), A2780 (non- serous ovarian cancer), and MDA-MB-231 (triple negative breast cancer / TNBC cells) were lysed in radio immunoprecipitation assay (RIPA) buffer. ER $\beta 1$ and ER $\beta 2$ protein expression was analyzed by immunoblotting with 
pan-ER $\beta$ antibody. (C) Left panel: ER $\beta 2$ and p53 Immunohistochemistry (IHC) staining of a typical tumor tissue core from a HGSOC patient tissue microarray (TMA). Right panel: Quantification of cytoplasmic and nuclear ER $\beta 2 \mathrm{H}$-Score in primary versus peritoneal metastasis HGSOC patients. Statistical analysis was performed on $\mathrm{H}$-sore from 44 patient primary tumors and their corresponding metastatic tumors. Error bars represent standard deviation (SD) and $p$ values were determined using unpaired student $t$ test. ${ }^{*}=<0.005$. (D,E) Kaplan-Meier survival curves in HGSOC patients showing tumors $(n=83)$ with high ER $\beta 2$ levels had worse prognosis in terms of both progression free survival (PFS) (D) and overall survival (OS) (E). Statistical analyses were performed in R4.0.3, all tests are two-sided and $p$-values less than 0.05 were considered significant. Survival analyses used Contal and O'Quigley's method to select a cut point. The uncropped Western Blot images can be found in Figure S8.
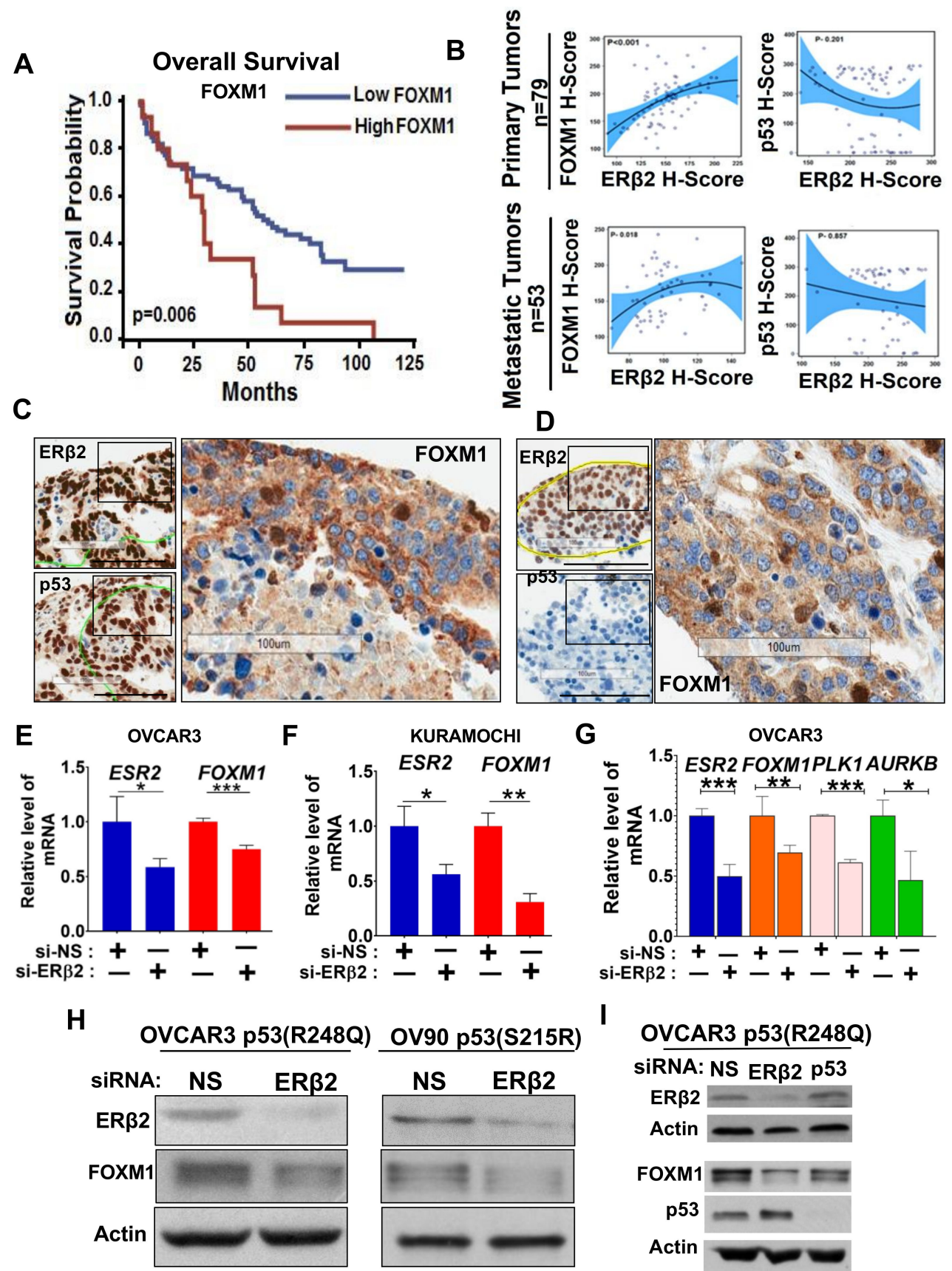

Figure 2. Upregulation of FOXM1 by ER $\beta 2$ is mutant p53-dependent. (A) Kaplan-Meier survival curves showing patients with HGSOC primary tumors expressing high FOXM1 $(n=79)$ had worse 
prognosis in terms of overall survival (OS). (B) Using the H-Scores, relationship between ER $\beta 2$ and FOXM1 or p53 in primary or metastatic tumors were analyzed using Spearman correlation methods, including 95\% confidence bands for the correlation coefficient estimates. Correlation between ER $\beta 2$ \& FOXM1 levels (left panel) and p53 \&ER 32 levels (right panel) in primary $(n=79)$ (top panel) versus metastatic $(n=53)$ (bottom panel) in HGSOC tumors on TMA. The $p$ values address the null hypothesis of no correlation between the two markers in each plot. The $p$ values have not been adjusted for multiple testing. (C,D) Representative IHC images of HGSOC patient tumors expressing (C) high and (D) low levels of ER 32 , p53 and FOXM1 (Scale bar: $100 \mu \mathrm{m})$. (E) OVCAR3 and (F) KURAMOCHI cells were treated with non-specific (si-NS) or ER 32 -specific siRNA (si-ER $\beta 2$ ) for $48 \mathrm{~h}$, followed by analysis of ESR2 and FOXM1 transcripts by qRT-PCR. (G) OVCAR3 cells were transiently transfected with non-specific siRNA (si-NS) or ESR2-specific siRNA for $48 \mathrm{~h}$. Post transfection, RNA levels of ESR2, FOXM1, and downstream targets of FOXM1 (PLK1 and AURKB genes) were determined by qRT-PCR. Statistical analysis in Figure 2E-G: Three independent experimental replicates were used for statistical analysis. The error bar represents SD, and $p$ values were analyzed using an unpaired Student's $t$-test. ${ }^{*}=<0.005,{ }^{* *}=0.001$, and ${ }^{* * *}=<0.0001$. (H) Expression of ERß2, FOXM1 and actin proteins in OVCAR3 and OV90 cells $48 \mathrm{~h}$ post-transfection with ESR2 siRNA were analyzed by immunoblotting. (I) OVCAR3 cells were transiently transfected with non-specific siRNA (si-NS) or ESR2-specific siRNA for $48 \mathrm{~h}$. Post transfection, an immunoblot for expression of ER $\beta 2$, FOXM1, and p53 proteins was performed. The uncropped Western Blot images can be found in Figure S9.

\section{Results}

\subsection{High ERß2 Expression Is Associated with Tumor Progression in HGSOC}

Isoforms of $E R \beta$, such as $E R \beta 1, E R \beta 2$, and $E R \beta 5$ have been reported to be expressed in HGSOC with important roles in signaling pathways, cell cycle regulation and apoptosis [28,30,41-43].

To assess the relative expression levels of ER $\beta 1$ and ER $\beta 2$ in HGSOC, we determined their RNA levels in extracts of HGSOC cell lines OV90, OVCAR-3, and KURAMOCHI as compared to the expression in FT282-c11, an untransformed fallopian tube epithelial cell line [44]. Levels of the ER $\beta 2$ mRNA (as determined by quantitative real time PCR/qRTPCR) was higher than ER $\beta 1$ mRNA levels in the HGSOC cells, but there was no significant difference in the isoform mRNA expression in FT282-c11 cells (Figure 1A). Similarly, ER $\beta 2$ protein levels were higher than ER $\beta 1$ levels in the HGSOC cell as compared to the levels in the untransformed FT282-c11 cells. Of note, in the non-serous ovarian cancer cell line A2780, ER $\beta 1$ levels were higher (Figure 1B). A triple negative breast cancer (TNBC) cell line, MDA-MB-231, where ER $\beta 1$ levels were higher than that of the ER $\beta 2$ levels is included as a positive control. ER $\beta 1$ and ER $\beta 2$ protein expression pattern in OVCAR3 and FT282-11 cells was further validated by transient expression of exogenous FLAG-ER $\beta 1$ and FLAG-ER $\beta 2$ and transient transfection of ER $\beta 2$ siRNA (Figure S3A-C). The specificity of the ER $\beta 2$ antibody was ascertained by knocking down ER $\beta 2$ with ER $\beta 2$-specific siRNA (Figure S3D). Consistent with these data, the IHC analysis of HGSOC tumor specimens on TMAs showed both the nuclear and cytoplasmic ER $\beta 2$ and p53 expression (Figure 1C). Furthermore, cytoplasmic expression of ER $\beta 2$ was higher in metastatic tumors $(n=44)$ as compared to primary tumors from which they progressed. However, p53 expression was similar in both the primary and metastatic tumors (Figure S2). We used IHC to determine the p53 status of tumors, as immunohistochemical analysis has been shown to be a robust method of inferring the presence of a p53 mutation in ovarian carcinomas [45]. A Kaplan-Meier analysis showed that high ER $\beta 2$ expression in primary tumors $(n=83)$ correlated with shorter PFS (Figure 1D) and OS (Figure 1E). ER $\alpha$ expression was very low both when analyzed by immunoblotting (Figure S1A) and by IHC in HGSOC tumors on the TMA (Figure S1B). 


\subsection{Upregulation of FOXM1 by ERß2 Is Mutant p53-Dependent}

Ovarian TCGA data have shown that the FOXM1 signaling is increased in HGSOC likely due to the universal presence of mutant p53 [2]. Therefore, we analyzed FOXM1 expression in our HGSOC patient tumor tissues by IHC on the TMAs. Kaplan Meier analysis showed that HGSOC patients with tumors $(n=83)$ with high FOXM1 levels had worse prognosis in terms of OS ( $p=0.006$ ) (Figure 2A).

Moreover, statistical analysis of IHC H-Score of ER $\beta 2$, FOXM1 and mutant p53 in HGSOC patient TMAs using Spearman correlation methods, including 95\% confidence bands for the correlation coefficient estimates, showed that the cytoplasmic ER $\beta 2$ and FOXM1 protein had significant linear co-relation in primary $(p<0.001)$ as well as metastatic $(p<0.018)$ tumors (Figure 2B, upper and bottom left panels, respectively). However, no such correlation between the levels of nuclear ER $\beta 2$ and p53 was observed (Figure 2B, right panels). FOXM1 protein was highly expressed in the cytoplasm in the primary as well as in the metastatic tumors (Figures 2C and S2). Additionally, ER $\beta 2$, mutant p53 and FOXM1 IHC staining data showed that high ER $\beta 2$ and high mutant p $53 \mathrm{H}$-Score is consistent with high cytoplasmic FOXM1 expression (Figure 2C), whereas low ER $\beta 2$ and p53 expression led to reduced cytoplasmic expression of FOXM1 (Figure 2D). Based on these data, along with the reported ability of ER $\beta 2$ to drive antiapoptotic pathways in HGSOC [30], we explored if ER $\beta 2$ alone or in association with mutant p53 had any role in the regulation of FOXM1 in HGSOC. FOXM1 mRNA levels were significantly reduced when ER $\beta 2$ was knocked down in OVCAR3 and KURAMOCHI cell lines (Figure 2E,F) suggesting a role for ER $\beta 2$ in the transcriptional regulation of FOXM1. Mutant p53 appeared to be necessary for enabling $E R \beta 2$ to upregulate downstream targets (PLK1 and AURKB) of FOXM1 as these genes were upregulated in OVCAR-3 cells harboring mutant p53 (Figure 2G). Consistent with the transcription data, depletion of ER $\beta 2$ led to a decrease in FOXM1 protein levels in OVCAR3 and OV90 cells expressing mutant p53 (Figure 2H). Furthermore, FOXM1 expression in OVCAR3 cells was decreased by depleting endogenous ER $\beta 2$ as well as mutantp53 (Figure 2I). These data suggest ER $\beta 2$ is necessary, but not sufficient, for activating FOXM1 transcription. The co-dependency of ER $\beta 2$ and mutant p53 in regulating FOXM1 is further substantiated by the finding that combined depletion of ER $\beta 2$ and mutant p53 resulted in more reduction in FOXM1 protein levels than when ER $\beta 2$ alone was depleted (Figure S5A). Of note, neither DPN (an agonist of ER $\beta$ ) nor Tamoxifen and PHTTP (antagonists of ER $\beta$ ) affected FOXM1 levels in OVCAR3 cells (Figure S5B).

\subsection{ER $\beta 2$ and Mutant $p 53$ Physically Interact and Are Recruited to the FOXM1 Gene Promoter} Leading to Activation of Transcription

We had previously reported that ER $\beta$ binds directly to p53 in breast cancer cells and tissues [35]. Here we analyzed the physical interaction between ER $\beta 2$ and mutant p53 in HGSOC. A proximity ligation assay (PLA) demonstrated a robust interaction between ER $\beta 2$ and p53 in situ in OVCAR3, KURAMOCHI, and OV90 cells, and relatively lower interaction in the FT282-C11 cells (Figure 3A,B). The specificity of interaction was ascertained by knocking down ER $\beta 2$ in OVCAR3 and OV-90 cells followed by PLA (Figure S3E). Consistent with the interaction, FOXM1 levels were higher in OVCAR3, KURAMOCHI and OV90 cells compared to that in FT282-c11 cells (Figure 3C). The physical interaction between ER $\beta 2$ and mutant p53 in OVCAR3 cells was orthogonally confirmed by co-immunoprecipitation assay (Figure 3D). Furthermore, we investigated if ER $\beta 2$-mutant p53 interaction occurs in HGSOC patient tumors, and if so, whether the extent of interaction differs between primary versus metastatic tumors. Toward this goal, we performed PLA on TMAs containing both primary $(n=88)$ and metastatic $(n=56)$ tumor tissues arrayed in triplicate. Importantly, metastatic tumors had more intense PLA signals compared to primary tumors (Figure 3E). The difference was highly significant as shown in the quantitation plot on the right. Importantly, p53 levels were high (consistent with mutant p53) along with elevated PLA signals (indicating ER $\beta 2$-mutant p53 interaction) in HGSOC (Figure S4A), while the p53 levels were low (consistent with wild type p53) and correspondingly negative for 
PLA signals (indicating lack of interaction between ER $\beta 2$ and wild type p53) in LGSOC (Figure S4B). Next, for testing the hypothesis that ER $\beta 2$ and mutant p 53 bind to the FOXM1 promoter leading to the upregulation of FOXM1 transcription, we performed a quantitative chromatin immunoprecipitation (q-ChIP) assay. We used the JASPAR database [46] to identify a consensus ER response element (ERE) (-2734 to -2719) in the FOXM1 gene promoter (Figure 3F). ER 32 bound to this site, but not to a non-specific region in the promoter (Figure 3G). Moreover, the binding was abolished when mutant p53 was knocked down (Figure 3H). These data on the interaction of ER 32 -mutant p53 complex on FOXM1 promoter chromatin are consistent with the co-dependency of ER $\beta 2$ and mutant p53 in upregulating FOXM1 protein levels noted before (Figure 2I).

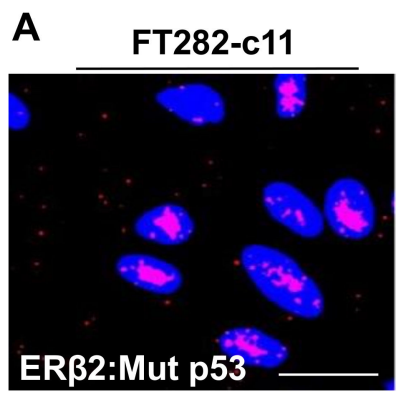

KURAMOCHI

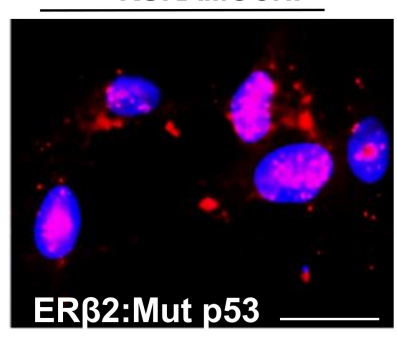

E

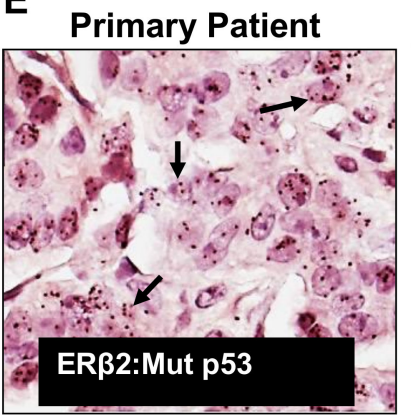

$\mathbf{F}$

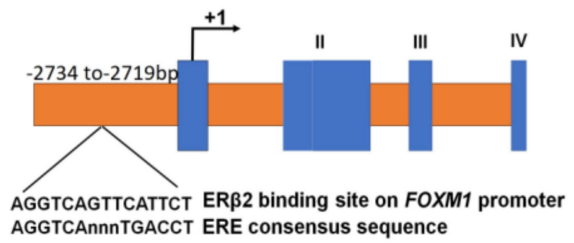
AGGTCAnnnTGACCT ERE consensus sequence
OVCAR-3

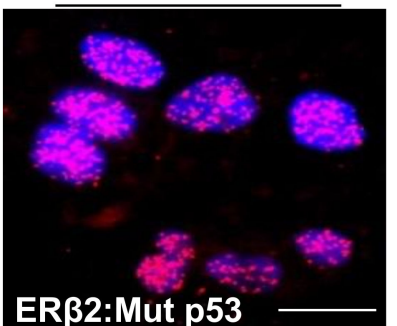

OV-90

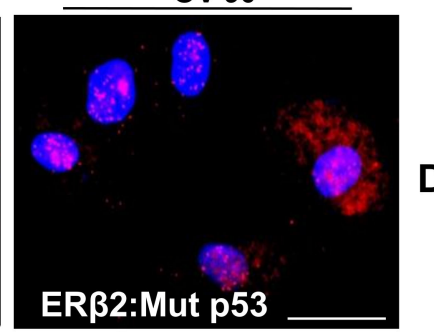

Metastatic Patient
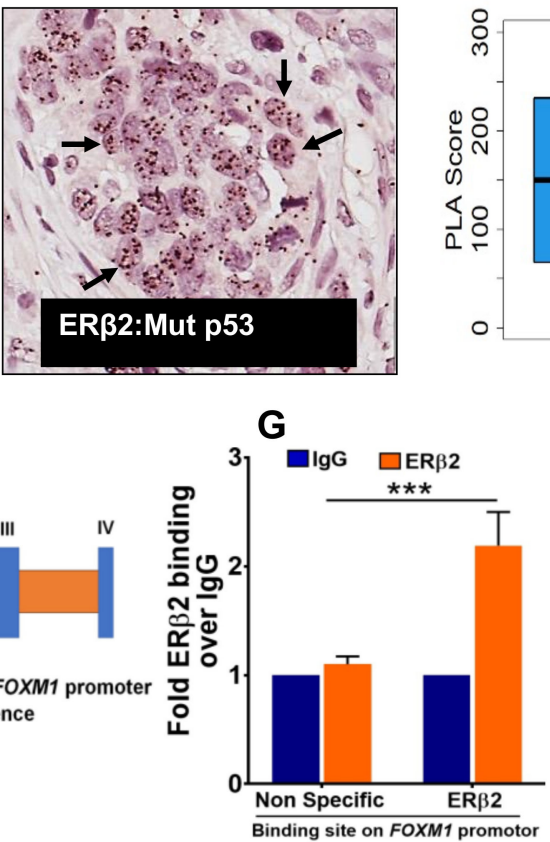
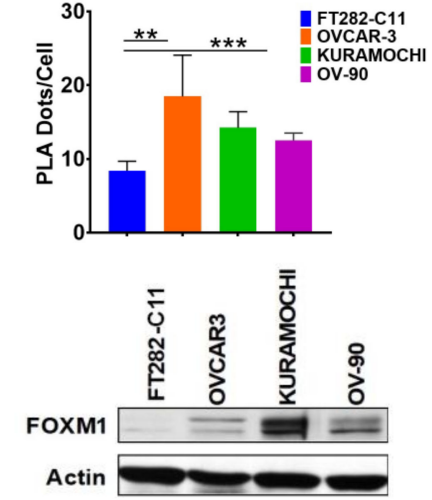

D
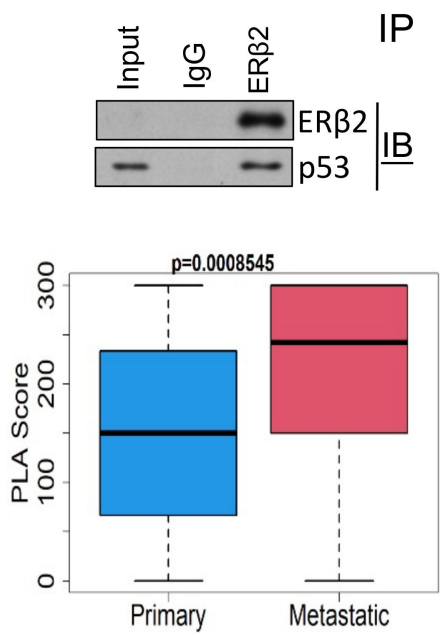

H

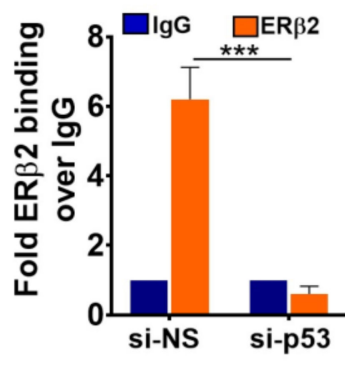

Figure 3. ER $\beta 2$ and mutant p53 physically interact and are recruited to the FOXM1 gene promoter leading to activation of transcription. (A) ER $\beta 2$-p53 interaction was analyzed by proximity ligation assay (PLA) in FT282-c11, OVCAR3, KURAMOCHI, and OV90 cells. Scale bar $=20 \mu \mathrm{m}$. (B) Quantification 
of PLA dots by ImageJ software. Statistical analysis was performed on average number of dots (per 300 nuclei) in three independent experiments. Error bar represents SD and $p$ values were analyzed using ANOVA test. ${ }^{* *}=0.001$, and ${ }^{* * *}=<0.0001$. (C) Immunoblot showing expression of endogenous FOXM1 in HGSOC cells. (D) Co-immunoprecipitation (Co-IP) of endogenous ER $\beta 2$ and mutant p53 was performed in OVCAR3 cells followed by immunoblotting with p53 and ER 32 antibodies. (E) ER 32 -mutant p53 interaction in primary versus peritoneal metastatic HGSOC patient tumors on TMAs were assayed by Bright-field PLA. Representative images are shown. Quantification (by $t$-test) of PLA scores for ER $\beta 2-$ mutant p53 interaction in primary versus peritoneal metastatic HGSOC patient tumors are shown on the right. PLA dots in 300 nuclei per patient tissue core in the TMA were manually counted using Bright-field microscopy. PLA scores $>100$ represent high interaction and dots $<100$ represent low interaction. (F) Schematic diagram of FOXM1 gene promotor with ER $\beta 2$-binding site. (G) Quantitative chromatin immunoprecipitation (qChIP) with ER $\beta 2$-specific antibody or IgG (negative control) on FOXM1 promoter was performed in OVCAR3 cells with or without depletion of ERß2 for $48 \mathrm{~h}$. (H) OVCAR3 cells transiently transfected with non-specific siRNA (si-NS) or TP53-specific siRNA. 48 h post-transfection, qChIP for ER 32 or IgG (negative control) on FOXM1 promoter was performed. Statistical analysis for data in Figure $3 \mathrm{G}, \mathrm{H}$ was performed based on three independent experiments. Error bar represents SD and $p$ values were analyzed using an unpaired Student's $t$-test. ${ }^{* * *}=<0.0001$. The uncropped Western Blot images can be found in Figure S10.

\subsection{ER $\beta 2$ Activates FOXM1 Expression and Confers Resistance to Carboplatin}

FOXM1 has been reported to confer resistance to chemotherapeutic agents such as platinum drugs in epithelial ovarian cancer [47]. We hypothesized that FOXM1 expression could be upregulated by ER $\beta 2$, leading to the resistance to carboplatin, an agent frequently used to treat HGSOC. To test this possibility, OVCAR3 cells were treated with multiple doses of carboplatin without and with siRNA-mediated transient depletion of ER $\beta 2$ in OVCAR3 cells (Figure S6A,B). Immunoblotting data showed that treatment with carboplatin $(4 \mu \mathrm{M})$ in ER 32 -depleted OVCAR3 cells decreased FOXM1 protein expression and increased carboplatin sensitivity resulting in up-regulated apoptosis as indicated by a sixfold increase in the cleaved PARP protein level (Figure 4A). Similar data were also observed on carboplatin and cisplatin treatment with the combination of ER $\beta 2$ knockdown in OV90 cells (Figure S6C). Consistent with these data, an Annexin V assay showed that ER $\beta 2$ depletion along with carboplatin treatment increased apoptosis more than two-fold compared to vehicle treated cells (Figure 4B; quantitation in Figure 4C). Furthermore, a cell survival assay demonstrated that treatment with $4 \mu \mathrm{M}$ carboplatin $72 \mathrm{~h}$ post-transfection with ER $\beta 2$ siRNA resulted in decreased cell survival as compared to cells treated with vehicle (Figure 4D).

\subsection{Disruption of ERß2-Mutant p53 Crosstalk Leads to HGSOC Cells Apoptosis}

Based on our findings that ER $\beta 2$-mutant p53 interaction leads to increased proliferation and resistance to chemotherapy, we hypothesized that disruption of this interaction would decrease the pro-proliferation effects in HGSOC cells. PRIMA-1 (p53 reactivation and induction of massive apoptosis) and its methylated form PRIMA- $1^{\text {MET }}$ are small molecules capable of converting mutant p53 to active wild type conformation and have been shown to overcome drug resistance in ovarian cancer cells [48,49]. First, we tested the effect of PRIMA- $1^{\text {MET }}$ on the interaction between ER $\beta 2$ and mutant p53 in OVCAR3 cells. The interaction was decreased considerably in response to the treatment (Figure 5A). This disruption of interaction by the drug leads to increased apoptosis (as evidenced by PARP cleavage) in a dose-dependent manner in OVCAR3 (Figure 5B) and OV90 cells (Figure S6). Importantly, neither the levels of ER $\beta 2$ nor mutant p53 were changed in response to the PRIMA-1 ${ }^{\text {MET }}$ treatment (Figure 5C), whereas both the RNA (Figure 5D) and protein (Figure 5E) levels of the prototypic p53-target and anti-proliferation protein p21 (CDKN1A) were increased in response to the drug treatment. Transcript levels of NOXA, a pro-apoptotic gene, was also increased by PRIMA-1 ${ }^{\mathrm{MET}}$ (Figure 5D). Furthermore, the combination of ER $\beta 2$ depletion with PRIMA-1 ${ }^{\mathrm{MET}}$ treatment led to a further increase in 
apoptosis as indicated by increased PARP cleavage in OVCAR3 cells (Figure 5F). A similar increase in apoptosis was also observed in OV90 cells (Figure S7) Based on our data, a potential model for the mechanism underlying drug resistance in HGSOC is shown in Figure 6A. Figure 6B shows how depleting pro-tumorigenic ER $\beta 2$ in combination with PRIMA- ${ }^{\text {MET }}$ that converts mutant p53 to WT conformation elicits increased apoptosis and overcomes resistance to carboplatin.

A VEH Carboplatin
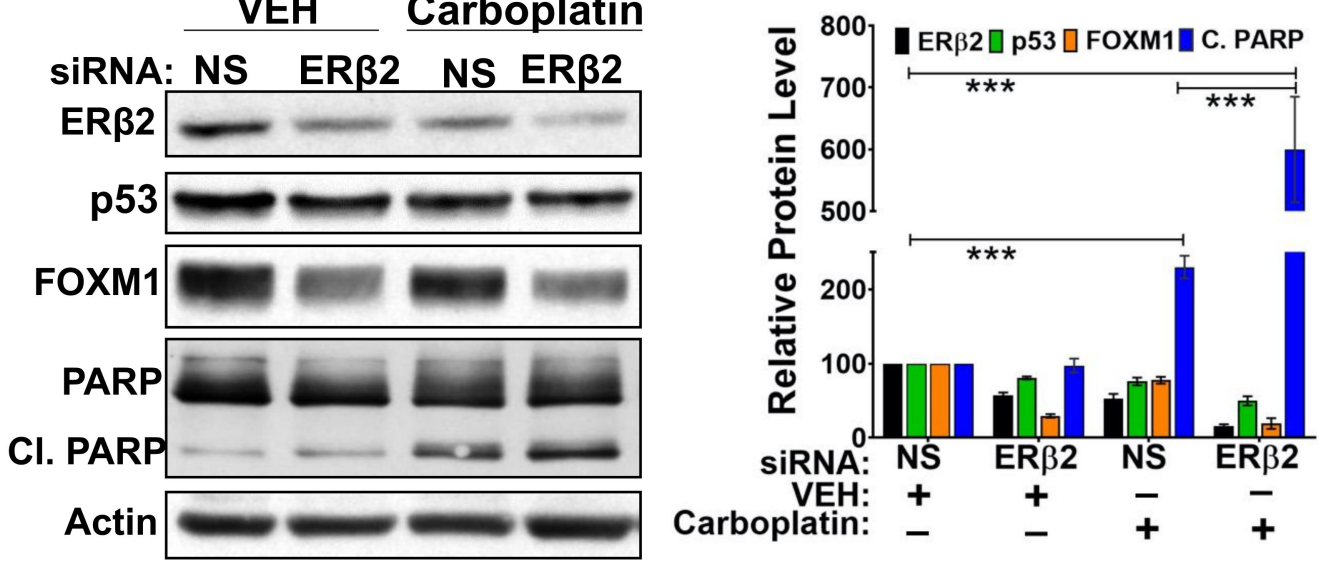

B

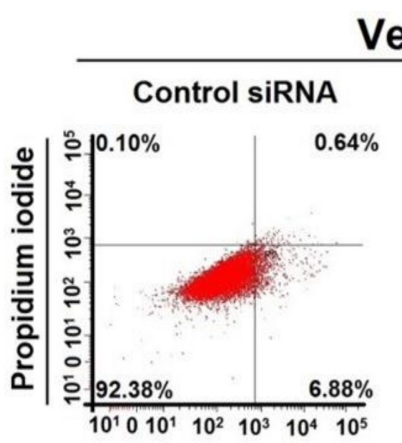

Vehicle ERßsiRNA

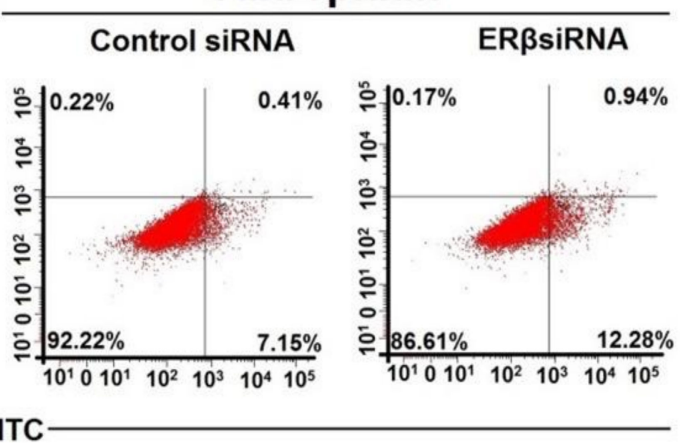

C

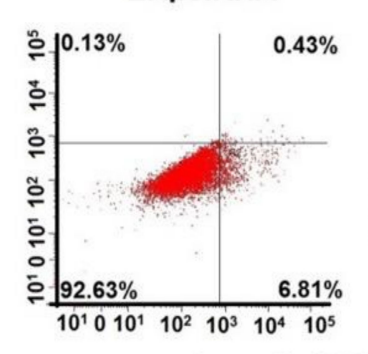

Annexin V-FITC

D
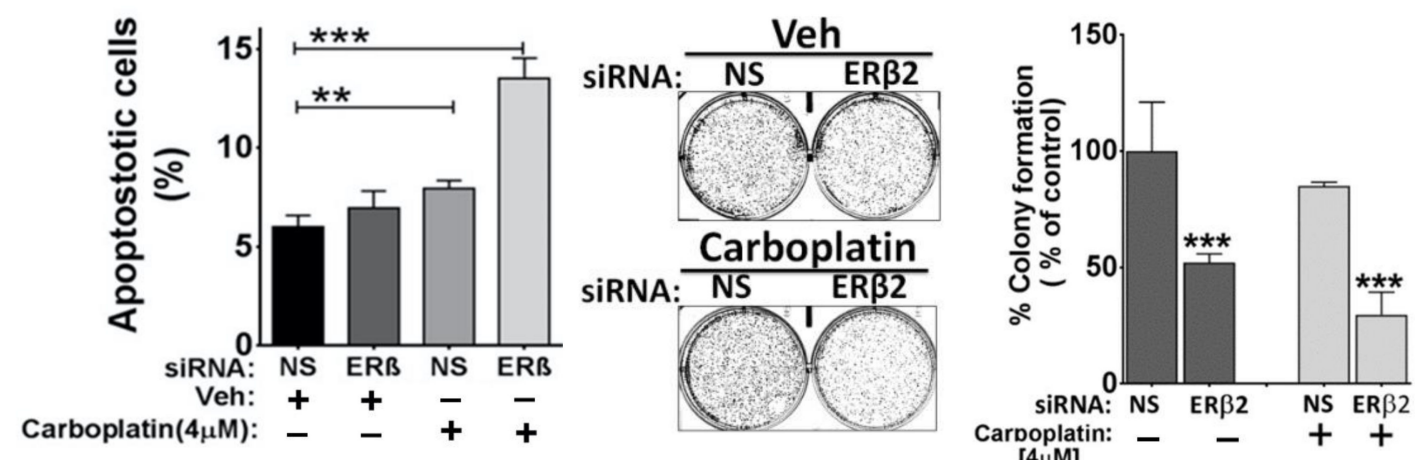

Figure 4. ER $\beta 2$ activates FOXM1 expression and confers resistance to carboplatin treatment. (A) OVCAR3 cells were transiently transfected with non-specific (ns-siRNA) or ERß2-specific siRNA for $48 \mathrm{~h}$, followed by carboplatin $(4 \mu \mathrm{M})$ treatment for $24 \mathrm{~h}$. Post treatment, cells were harvested and expression levels of FOXM1, p53, ER 32 , PARP and cleaved PARP were determined by immunoblotting. A representative immunoblot from three experimental replicates is shown. Right panel shows the quantification of FOXM1, p53, ER 32 , PARP and cleaved PARP after normalization to actin levels. 
Statistical analysis was performed on average quantity of each protein on the immunoblot from three independent experiments. Error bar represents SD and $p$ values were analyzed using ANOVA test. $* * *=<0.0001$. (B) Flow cytometry analysis of OVCAR3 cells post-transfection with control siRNA or ER $\beta 2$ siRNA for $48 \mathrm{~h}$ and treated with vehicle or carboplatin $(4 \mu \mathrm{M})$. Cells were double stained with Annexin V-FITC and Propidium Iodide (PI) for apoptosis assay. (C) Quantitation of data shown in B. Bar graph shows fold change of Annexin +/PI-cells normalized with untreated control. Statistical analysis was performed using average quantity of annexin $\mathrm{V}$ from three independent experiments. Error bar represents SD and $p$ values were analyzed using ANOVA test. ${ }^{* *}=0.001$, and ${ }^{* * *}=<0.0001$. (D) OVCAR3 cells $48 \mathrm{~h}$ post-transfection with non-specific (ns-siRNA) or ER $\beta 2$-specific siRNA were treated with carboplatin $(4 \mu \mathrm{M})$. Treated cells were re-seeded, and after nine days colonies were stained with crystal violet and quantified using a Bright-field microscope. Right panel shows the quantification colonies of OVCAR3 cells. Statistical analysis was performed using average percentage of colony formation from three independent experiments. Error bar represents SD and $p$ values were analyzed using an unpaired Student's $t$-test. ${ }^{* *}=<0.0001$ Error bars represent standard deviation (SD). Veh: Vehicle. The uncropped Western Blot images can be found in Figure S11.

A

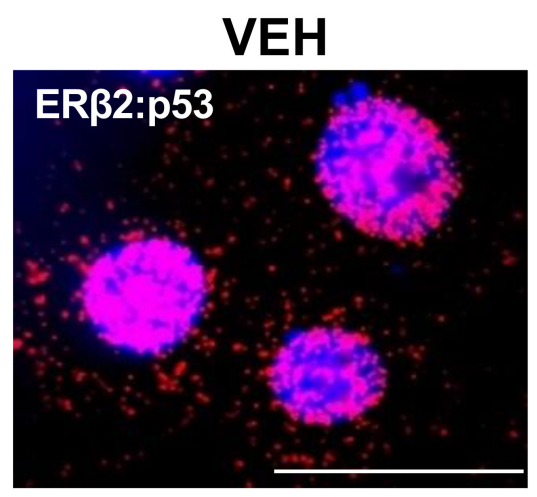

PRIMA-1-MET
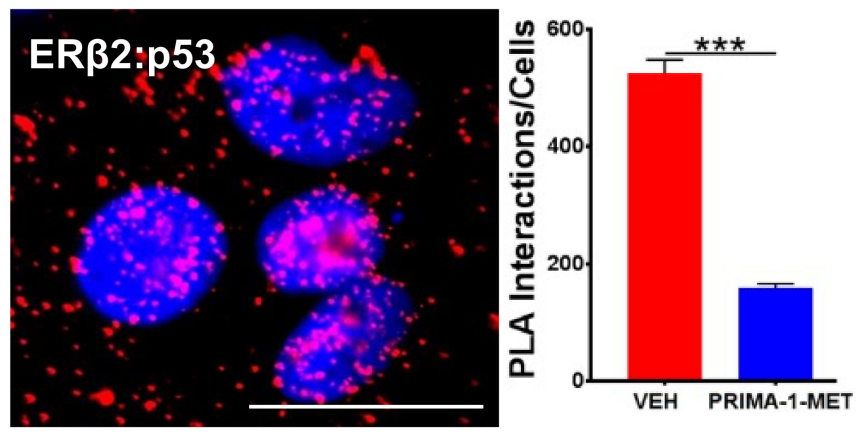

B

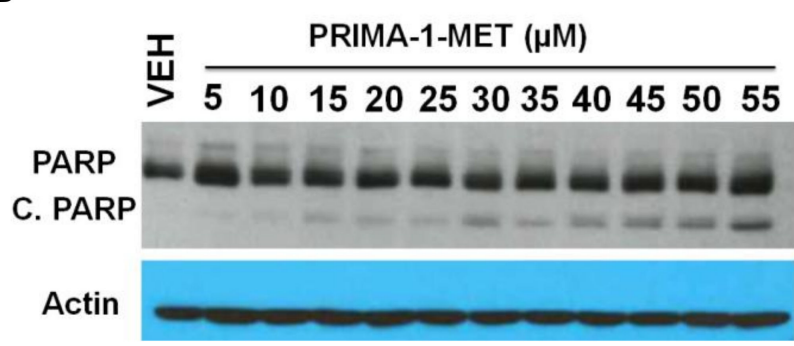

C

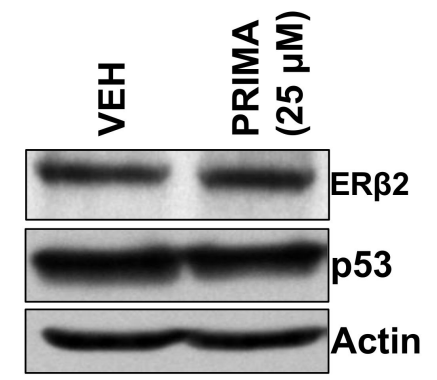

D

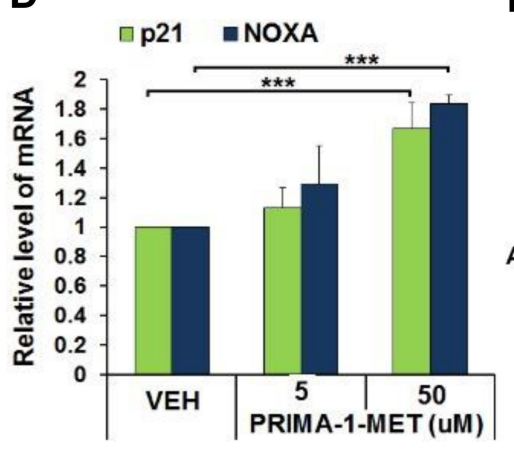

E

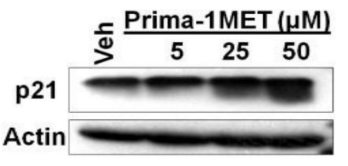

$\mathbf{F}$

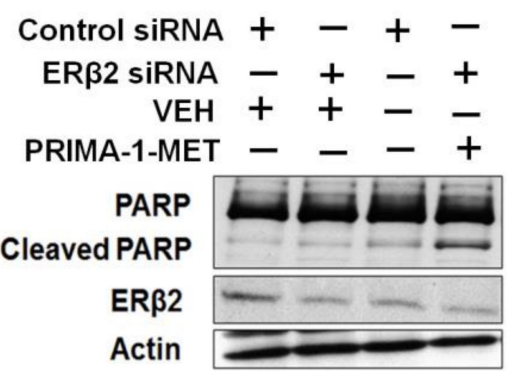

Figure 5. Disruption of ERß2-mutant p53 interaction leads to apoptosis. (A) OVCAR3 cells treated with vehicle (left panel) or $25 \mu \mathrm{M}$ PRIMA-1MET. Post-24 h treatment, PLA was performed 
for ER $\beta 2$-mutant p53 interaction (Scale bar $=20 \mu \mathrm{m}$ ). Right panel: Quantification of the ER $\beta 2$ : p53 PLA dots with ImageJ software. Statistical analysis was performed on average number of dots (per 300 nuclei) in three independent experiments. Error bar represents SD and p-values were analyzed using ANOVA test. ${ }^{* *}=<0.0001$. (B) Dose titration of PRIMA-1MET in OVCAR3 cells and determining apoptosis by PARP cleavage assay using immunoblotting. (C) Expression of ER $\beta 2$ and p53 proteins in OVCAR3 cells $24 \mathrm{~h}$ post-treatment with PRIMA-1MET $(25 \mu \mathrm{M})$ was analyzed by immunoblotting. (D) OVCAR3 cells were treated with vehicle or different doses of PRIMA-1MET $(5 \mu \mathrm{M}, 50 \mu \mathrm{M})$ for $24 \mathrm{~h}$ and transcripts of p21 and NOXA were analyzed with qRT-PCR. Statistical analysis was performed on three independent experiments. Error bar represents SD and p-values were analyzed using ANOVA test ${ }^{* * *}=<0.0001$. (E) OVCAR3 cells were treated with vehicle or different doses $(5 \mu \mathrm{M}, 25 \mu \mathrm{M}, 50 \mu \mathrm{M})$ of PRIMA-1MET for $24 \mathrm{~h}$ followed by determination of p21 protein expression by immunoblotting. (F) OVCAR3 cells were transfected with or without ER $\beta 2$ siRNA, followed by treatment with vehicle or $25 \mu \mathrm{M}$ PRIMA-1MET for $24 \mathrm{~h}$. Post treatment, PARP, Cleaved PARP and ER $\beta 2$ expression was analyzed by immunoblotting. VEH: Vehicle. The uncropped Western Blot images can be found in Figures S12 and S13.

A

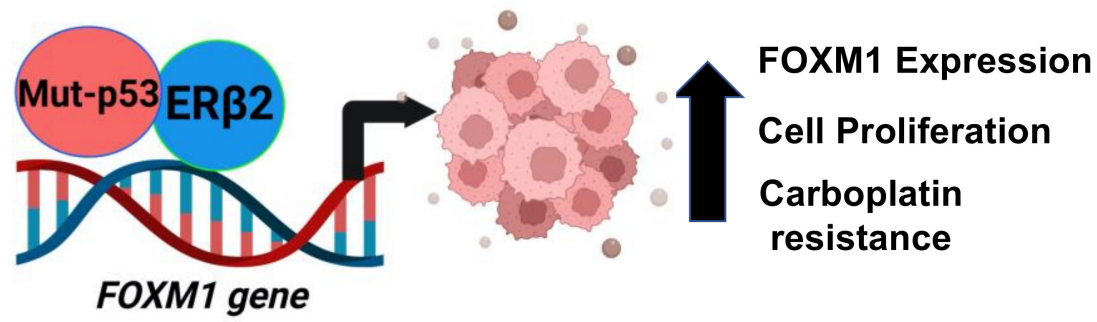

B

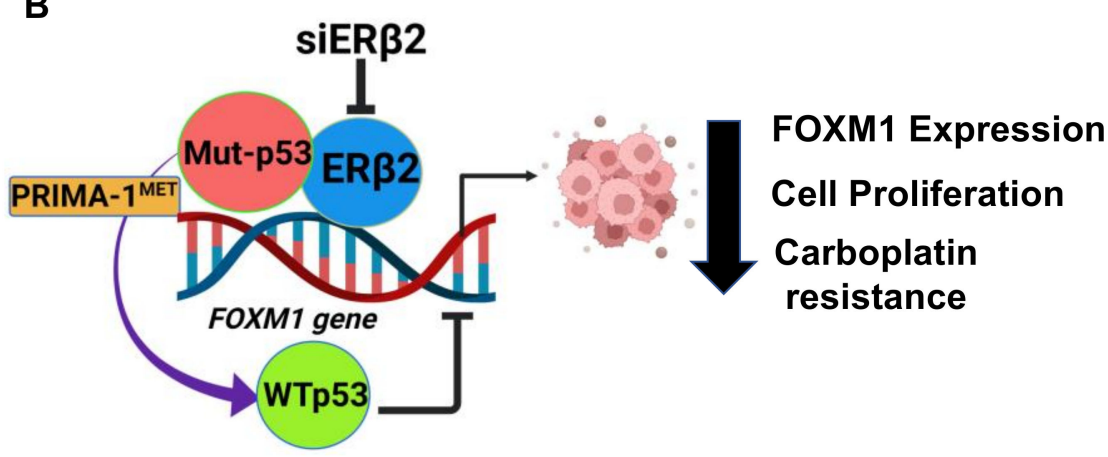

Figure 6. Working model for ER $32-$ p53-FOXM1 signaling axis and therapeutic resistance in HGSOC. (A) Working model where ER $\beta 2$ interacting with mutant p53 upregulates FOXM1 transcription leading to increased proliferation and therapeutic resistance. (B) Model for reversal of effects in A when FOXM1 transcription gets downregulated by the combined action of ESR2-specific siRNA and PRIMA-1 ${ }^{\text {MET }}$. The figure was created with Biorender.com (access on: 13 November 2021).

\section{Discussion}

To the best of our knowledge, this is the first report on the crosstalk between ER $\beta 2$ and mutant p53 to upregulate FOXM1 expression, proliferation, and therapeutic resistance in HGSOC cells and patient tumor tissues. FOXM1 was previously reported to be a target of transcriptional repression by wild type p53 [32,33] and the repression by p53 was shown to be E2F-dependent [50]. Analysis of the TCGA of HGSOC showed that there is almost universal ( $96 \%$ ) expression of mutant or null alleles of p53 in these tumors along with high levels of FOXM1 and the activation of pro-proliferation pathways downstream [2]. In addition to being regulated by p53, FOXM1 has been reported to be regulated by ER $\beta$ as well. However, results from these studies have been inconclusive. While FOXM1 was one of 
the genes downregulated when ER $\beta 1$ was exogenously expressed in breast cancer cells [51], it was not affected by ER $\beta 1$ overexpression in another study [52]. Neither study looked at the effect of ER $\beta$ isomers such as ER $\beta 2$ that has been suggested to be pro-oncogenic. ER $\beta 2$ localized to the mitochondria was reported to interact with BAD and inhibit apoptosis [30]. It is becoming increasingly clear that understanding the role of wild type and mutant p53 is of high relevance to the etiology and treatment of HGSOC $[13,14]$. Targeting mutant p53 interaction with partner proteins is a promising therapeutic strategy [53]. ER $\beta$ 's oncogenic role may not only be isoform specific but may also depend on the mutational context of partner proteins such as p53 [35]. Here we demonstrate that ER $\beta 2$, but not ER $\beta 1$, is the prominent ER $\beta$ form in HGSOC cells, whereas ER $\beta 1$ is the major isoform expressed in the non-serous cell line A2780. The normal fallopian tube cell line FT282-c11 did not express much of either isoform. Furthermore, ER $\beta 2$ levels were higher in metastatic HGSOC compared to the primary tumors they had evolved from and were correlated with worse PFS and OS. Of note, ER $\alpha$ levels were relatively low in HGSOC patient tissues we used for our studies, consistent with the report of a large study conducted by the Ovarian Tumor Tissue Analysis consortium in 1742 HGSOC cases that showed that ER $\alpha$ was not associated with improved HGSOC survival [18]. Importantly, there was positive correlation between ERß2 expression and FOXM1 levels in HGSOC patient tumors, and higher levels of FOXM1 correlated with low OS. Our molecular analyses revealed a co-dependency between ER $\beta 2$ and mutant p53 in upregulating FOXM1 in HGSOC cells. In situ PLA showed that ER $\beta 2$ physically interacted with mutant p53 both in the HGSOC cells and in patient tumors. The importance of such co-dependency and interaction in upregulating FOXM1 transcription was ascertained by a qChIP assay that showed mutant p53-depencent $\mathrm{ER} \beta 2$ binding to the FOXM1 gene promoter. FOXM1 drives ovarian oncogenesis in multiple ways including inducing resistance to chemotherapeutic agents such as carboplatin [34]. Our data that the ablation of ER $\beta 2$ increases sensitivity of OVCAR3 cells to carboplatin by increasing apoptosis and decreasing cell proliferation suggest that ER $\beta 2$ in concert with mutant p53 is a major driver of carboplatin resistance in HGSOC. This conclusion is further strengthened by the observation that conversion of mutant p53 to wild type conformation by PRIMA- $1^{\mathrm{MET}}$ resulted in decreased ER $\beta 2-p 53$ interaction leading to a dose-dependent increase in p21 (CDKNIA) and NOXA expression and increased apoptosis. Moreover, when PRIMA- ${ }^{\text {MET }}$ treatment was combined with ER $\beta 2$ knockdown, there was further enhancement of apoptosis. These observations led to a working model where ER $\beta 2$ interacting with mutant p53 upregulates FOXM1 transcription leading to increased proliferation and therapeutic resistance (Figure 6A). This effect is reversed when FOXM1 transcription gets downregulated by the combined action of ER $\beta 2$-specific siRNA and PRIMA-1 ${ }^{\text {MET }}$ (Figure 6B).

Although the importance of ER $\beta$ in ovarian cancer has been widely recognized, the issue of whether it is pro- or anti-oncogenic remains unsettled [15,54]. The lack of well-defined molecular studies to determine the major oncogenic ER $\beta$ isoform that is predominantly expressed in HGSOC has been mainly responsible for disparate reports on the role of ER $\beta$. The current study at least partially resolves this controversy. Furthermore, our study shines light on the importance of proteins such as ER $\beta$ that partner with mutant p53 either to drive or suppress oncogenesis depending on a particular cancer context. In the case of HGSOC, ER $\beta 2$ cooperates with mutant p53 to drive oncogenesis and drug resistance. Of note, although HGSOC and TNBC share several molecular similarities, our data showed that unlike in HGSOC cells, levels of ER $\beta 1$ are higher than that of ER $\beta 2$ in the TNBC cell line MDA-MB-231. Further studies are needed to decipher whether this is limited to a few cell lines or is a general difference between HGSOC and TNBC cells, and if so, its differential roles in driving these two types of aggressive cancers. It is important to note that although ER $\beta 2$ interacted with the p53 mutants expressed in the cell lines and tumor tissues we used for this study, it is quite possible that ER $\beta 2$ may not interact with all p53 mutants, as different mutations of p53 have been reported to affect tumor growth 
and progression differently. Therefore, stratifying HGSOC based on heterogeneity of p53 mutations and $E R \beta$ could be promising in developing new therapeutic strategies.

\section{Conclusions}

This study reveals the interaction between ER $\beta 2$ and mutant p53 and functional co-dependency in HGSOC cell lines and patient tumors. We have identified a novel ER $\beta 2$-mutant p53-FOXM1 signaling axis that drives increased proliferation, inhibition of apoptosis, and resistance to carboplatin therapy in HGSOC cell lines and affects the DFS and OS of patients. Drug-induced conversion of mutant p53 to wild type conformation when combined with depletion of ER $\beta 2$ mitigates these effects. A working model based on these observations is shown in Figure 6. These findings have important clinical implications and could trigger new mechanistic studies on the role of ER $\beta$ and mutant p53 toward developing new therapeutic strategies against HGSOC. An in-depth understanding of the molecular mechanisms by which different p53 mutations and different isoforms of ER $\beta$ crosstalk and impinge on driving ovarian oncogenesis should further refine these strategies.

Supplementary Materials: The following supporting information can be downloaded at: https: / /www.mdpi.com/article/10.3390/cancers14051120/s1, Figure S1: ER $\beta$, but not ER $\alpha$, is the major hormone receptor in HGSOC; Figure S2: Immunohistochemistry (IHC) H Scores of FOXM1 and p53 in primary versus metastatic patient tumors; Figure S3: Induction of apoptosis by carboplatin and cisplatin; Figure S4: Protein levels of ER $\beta 2$ and p53 (IHC) and interaction between ER $\beta 2$ and p53 in HGSOC (A) and LGSOC (B); Figure S5A: Both ER $\beta 2$ and mutant p53 are necessary to upregulate FOXM1; Figure S5B: Effect of ER $\beta$ ligands on FOXM1 expression; Figure S6: Induction of apoptosis by carboplatin and cisplatin; Figure S7: Treatment with PRIMA-1MET induces apoptosis in OV-90 cells; Figures S8, S9, S19, S11, S12 and S13: Uncropped Western blot images; Table S1: Oligonucleotide primers; Table S2: Antibodies.

Author Contributions: Conceptualization, G.M.D., C.C.O.; methodology, C.C.O., G.M.D.; validation, C.C.O., and G.M.D.; formal analysis, A.M., K.H.E.; investigation, C.C.O., P.R., N.G.; resources, GMD., K.O.O., E.Z., P.K.S.; writing-original draft preparation, G.M.D., C.C.O.; writing-review and editing, G.M.D., C.C.O., N.G, E.Z.; visualization, C.C.O.; supervision, G.M.D.; project administration, G.M.D.; funding acquisition, G.M.D. All authors have read and agreed to the published version of the manuscript.

Funding: This research was funded by a Pilot Study Award from The Marsha Rivkin Center for Ovarian Cancer Research (to GMD), grants from the Roswell Park Alliance Foundation (to GMD), National Cancer Institute (NCI/NIH grant 5R01CA251545 (to GMD), and a Developmental Research Project (DRP) award (to GMD) from National Cancer Institute (NCI/NIH) Ovarian Cancer Specialized Programs of Research Excellence (SPORE) grant (P50CA159981) to Roswell Park and University of Pittsburgh. This work was supported by the NCI grant P30CA016056 involving the use of Roswell Park Comprehensive Cancer Center's Pathology Network, Data Bank and BioRepository, Flow and Image Cytometry, Biostatistics and Statistical Genomics, and Genomics Shared Resources. The Pathology Network was also supported by National Center for Research Resources grant S10OD019977.

Institutional Review Board Statement: The study was conducted in accordance with the Declaration of Helsinki and approved by the Institutional Review Board of Roswell Park Comprehensive Cancer Center (protocol code BDR 060615; Date of approval: 6 August 2015).

Informed Consent Statement: Not applicable.

Data Availability Statement: Data sharing is not applicable to any data included in this article.

Acknowledgments: The authors acknowledge Michael Higgins and Adam Karpf for generously providing ovarian cell lines; Xinjiang Wang for carboplatin; and Angela Omilian and Wiam Bshara for their help in the IHC analysis of TMAs.

Conflicts of Interest: The authors declare that they have no conflicts of interest. The funders had no role in the design of the study; in the collection, analyses, or interpretation of data; in the writing of the manuscript, or in the decision to publish the results. 


\section{References}

1. Torre, L.A.; Trabert, B.; DeSantis, C.E.; Miller, K.D.; Samimi, G.; Runowicz, C.D.; Gaudet, M.M.; Jemal, A.; Siegel, R.L. Ovarian cancer statistics, 2018. CA Cancer J. Clin. 2018, 68, 284-296. [CrossRef] [PubMed]

2. Cancer Genome Atlas Research Network. Integrated genomic analyses of ovarian carcinoma. Nature 2011, 474, 609-615. [CrossRef] [PubMed]

3. Kim, J.; Park, E.Y.; Kim, O.; Schilder, J.M.; Coffey, D.M.; Cho, C.H.; Bast, R.C., Jr. Cell Origins of High-Grade Serous Ovarian Cancer. Cancers 2018, 10, 433. [CrossRef] [PubMed]

4. Meserve, E.E.K.; Brouwer, J.; Crum, C.P. Serous tubal intraepithelial neoplasia: The concept and its application. Mod. Pathol. 2017, 30, 710-721. [CrossRef]

5. Zhang, S.; Dolgalev, I.; Zhang, T.; Ran, H.; Levine, D.A.; Neel, B.G. Both fallopian tube and ovarian surface epithelium are cells-of-origin for high-grade serous ovarian carcinoma. Nat. Commun. 2019, 10, 5367. [CrossRef]

6. Ahmed, A.A.; Etemadmoghadam, D.; Temple, J.; Lynch, A.G.; Riad, M.; Sharma, R.; Stewart, C.; Fereday, S.; Caldas, C.; Defazio, A.; et al. Driver mutations in TP53 are ubiquitous in high grade serous carcinoma of the ovary. J. Pathol. 2010, 221, 49-56. [CrossRef]

7. Saleh, A.; Perets, R. Mutated p53 in HGSC-From a Common Mutation to a Target for Therapy. Cancers 2021, 13, 3465. [CrossRef]

8. Tuna, M.; Ju, Z.; Yoshihara, K.; Amos, C.I.; Tanyi, J.L.; Mills, G.B. Clinical relevance of TP53 hotspot mutations in high-grade serous ovarian cancers. Br. J. Cancer 2020, 122, 405-412. [CrossRef] [PubMed]

9. $\quad$ Ren, Y.A.; Mullany, L.K.; Liu, Z.; Herron, A.J.; Wong, K.K.; Richards, J.S. Mutant p53 Promotes Epithelial Ovarian Cancer by Regulating Tumor Differentiation, Metastasis, and Responsiveness to Steroid Hormones. Cancer Res. 2016, 76, $2206-2218$. [CrossRef] [PubMed]

10. Brachova, P.; Mueting, S.R.; Carlson, M.J.; Goodheart, M.J.; Button, A.M.; Mott, S.L.; Dai, D.; Thiel, K.W.; Devor, E.J.; Leslie, K.K. TP53 oncomorphic mutations predict resistance to platinum and taxanebased standard chemotherapy in patients diagnosed with advanced serous ovarian carcinoma. Int. J. Oncol. 2015, 46, 607-618. [CrossRef] [PubMed]

11. Silwal-Pandit, L.; Langerod, A.; Borresen-Dale, A.L. TP53 Mutations in Breast and Ovarian Cancer. Cold Spring Harb. Perspect. Med. 2017, 7, a026252. [CrossRef] [PubMed]

12. Kang, H.J.; Chun, S.M.; Kim, K.R.; Sohn, I.; Sung, C.O. Clinical relevance of gain-of-function mutations of p53 in high-grade serous ovarian carcinoma. PLoS ONE 2013, 8, e72609. [CrossRef] [PubMed]

13. Iwanicki, M.P.; Chen, H.Y.; Iavarone, C.; Zervantonakis, I.K.; Muranen, T.; Novak, M.; Ince, T.A.; Drapkin, R.; Brugge, J.S. Mutant p53 regulates ovarian cancer transformed phenotypes through autocrine matrix deposition. JCI Insight 2016, 1, e86829. [CrossRef]

14. Labidi-Galy, S.I.; Papp, E.; Hallberg, D.; Niknafs, N.; Adleff, V.; Noe, M.; Bhattacharya, R.; Novak, M.; Jones, S.; Phallen, J.; et al. High grade serous ovarian carcinomas originate in the fallopian tube. Nat. Commun. 2017, 8, 1093. [CrossRef]

15. Langdon, S.P.; Herrington, C.S.; Hollis, R.L.; Gourley, C. Estrogen Signaling and Its Potential as a Target for Therapy in Ovarian Cancer. Cancers 2020, 12, 1647. [CrossRef]

16. Andersen, C.L.; Sikora, M.J.; Boisen, M.M.; Ma, T.; Christie, A.; Tseng, G.; Park, Y.; Luthra, S.; Chandran, U.; Haluska, P.; et al. Active Estrogen Receptor-alpha Signaling in Ovarian Cancer Models and Clinical Specimens. Clin. Cancer Res. 2017, 23, 3802-3812. [CrossRef] [PubMed]

17. Lau, K.M.; Mok, S.C.; Ho, S.M. Expression of human estrogen receptor-alpha and -beta, progesterone receptor, and androgen receptor mRNA in normal and malignant ovarian epithelial cells. Proc. Natl. Acad. Sci. USA 1999, 96, 5722-5727. [CrossRef]

18. Sieh, W.; Kobel, M.; Longacre, T.A.; Bowtell, D.D.; de Fazio, A.; Goodman, M.T.; Hogdall, E.; Deen, S.; Wentzensen, N.; Moysich, K.B.; et al. Hormone-receptor expression and ovarian cancer survival: An Ovarian Tumor Tissue Analysis consortium study. Lancet Oncol. 2013, 14, 853-862. [CrossRef]

19. Matsuo, K.; Sheridan, T.B.; Mabuchi, S.; Yoshino, K.; Hasegawa, K.; Studeman, K.D.; Im, D.D.; Rosenshein, N.B.; Roman, L.D.; Sood, A.K. Estrogen receptor expression and increased risk of lymphovascular space invasion in high-grade serous ovarian carcinoma. Gynecol. Oncol. 2014, 133, 473-479. [CrossRef]

20. Ciucci, A.; Zannoni, G.F.; Travaglia, D.; Petrillo, M.; Scambia, G.; Gallo, D. Prognostic significance of the estrogen receptor beta (ERbeta) isoforms ERbeta1, ERbeta2, and ERbeta5 in advanced serous ovarian cancer. Gynecol. Oncol. 2014, 132, 351-359. [CrossRef]

21. Drummond, A.E.; Fuller, P.J. Ovarian actions of estrogen receptor-beta: An update. Semin. Reprod. Med. 2012, 30, 32-38. [CrossRef]

22. Bossard, C.; Busson, M.; Vindrieux, D.; Gaudin, F.; Machelon, V.; Brigitte, M.; Jacquard, C.; Pillon, A.; Balaguer, P.; Balabanian, K.; et al. Potential role of estrogen receptor beta as a tumor suppressor of epithelial ovarian cancer. PLoS ONE 2012, 7, e44787. [CrossRef] [PubMed]

23. Docquier, A.; Garcia, A.; Savatier, J.; Boulahtouf, A.; Bonnet, S.; Bellet, V.; Busson, M.; Margeat, E.; Jalaguier, S.; Royer, C.; et al. Negative regulation of estrogen signaling by ERbeta and RIP140 in ovarian cancer cells. Mol. Endocrinol. 2013, 27, $1429-1441$. [CrossRef]

24. Liu, J.; Viswanadhapalli, S.; Garcia, L.; Zhou, M.; Nair, B.C.; Kost, E.; Rao Tekmal, R.; Li, R.; Rao, M.K.; Curiel, T.; et al. Therapeutic utility of natural estrogen receptor beta agonists on ovarian cancer. Oncotarget 2017, 8, 50002-50014. [CrossRef]

25. Pinton, G.; Nilsson, S.; Moro, L. Targeting estrogen receptor beta (ERbeta) for treatment of ovarian cancer: Importance of KDM6B and SIRT1 for ERbeta expression and functionality. Oncogenesis 2018, 7, 15. [CrossRef] 
26. Schuler-Toprak, S.; Moehle, C.; Skrzypczak, M.; Ortmann, O.; Treeck, O. Effect of estrogen receptor beta agonists on proliferation and gene expression of ovarian cancer cells. BMC Cancer 2017, 17, 319. [CrossRef]

27. Aust, S.; Horak, P.; Pils, D.; Pils, S.; Grimm, C.; Horvat, R.; Tong, D.; Schmid, B.; Speiser, P.; Reinthaller, A.; et al. The prognostic value of estrogen receptor beta and proline-, glutamic acid- and leucine-rich protein 1 (PELP1) expression in ovarian cancer. BMC Cancer 2013, 13, 115. [CrossRef]

28. Chan, K.K.; Wei, N.; Liu, S.S.; Xiao-Yun, L.; Cheung, A.N.; Ngan, H.Y. Estrogen receptor subtypes in ovarian cancer: A clinical correlation. Obstet. Gynecol. 2008, 111, 144-151. [CrossRef] [PubMed]

29. Haring, J.; Schuler, S.; Lattrich, C.; Ortmann, O.; Treeck, O. Role of estrogen receptor beta in gynecological cancer. Gynecol. Oncol. 2012, 127, 673-676. [CrossRef] [PubMed]

30. Ciucci, A.; Zannoni, G.F.; Travaglia, D.; Scambia, G.; Gallo, D. Mitochondrial estrogen receptor beta2 drives antiapoptotic pathways in advanced serous ovarian cancer. Hum. Pathol. 2015, 46, 1138-1146. [CrossRef]

31. van Kruchten, M.; van der Marel, P.; de Munck, L.; Hollema, H.; Arts, H.; Timmer-Bosscha, H.; de Vries, E.; Hospers, G.; Reyners, A. Hormone receptors as a marker of poor survival in epithelial ovarian cancer. Gynecol. Oncol. 2015, 138, 634-639. [CrossRef] [PubMed]

32. Barsotti, A.M.; Prives, C. Pro-proliferative FoxM1 is a target of p53-mediated repression. Oncogene 2009, 28, 4295-4305. [CrossRef]

33. Pandit, B.; Halasi, M.; Gartel, A.L. p53 negatively regulates expression of FoxM1. Cell Cycle 2009, 8, 3425-3427. [CrossRef] [PubMed]

34. Liu, C.; Barger, C.J.; Karpf, A.R. FOXM1: A Multifunctional Oncoprotein and Emerging Therapeutic Target in Ovarian Cancer. Cancers 2021, 13, 3065. [CrossRef]

35. Mukhopadhyay, U.K.; Oturkar, C.C.; Adams, C.; Wickramasekera, N.; Bansal, S.; Medisetty, R.; Miller, A.; Swetzig, W.M.; Silwal-Pandit, L.; Borresen-Dale, A.L.; et al. TP53 Status as a Determinant of Pro- vs Anti-Tumorigenic Effects of Estrogen Receptor-Beta in Breast Cancer. J. Natl. Cancer Inst. 2019, 111, 1202-1215. [CrossRef]

36. Das, G.M.; Mukhopadhyay, U.K.; Bansal, S.; Medisetty, R.; Swetzig, W.; Wickramasekera, N. Tumor suppressor p53 status as a determinant of estrogen receptor beta signaling in breast cancer. FASEB J. 2013, 27, 1031.21. [CrossRef]

37. Bado, I.; Nikolos, F.; Rajapaksa, G.; Gustafsson, J.A.; Thomas, C. ERbeta decreases the invasiveness of triple-negative breast cancer cells by regulating mutant p53 oncogenic function. Oncotarget 2016, 7, 13599-13611. [CrossRef] [PubMed]

38. Oturkar, C.C.; Miller, A.; Zsiros, E.; Das, G.M. Estrogen receptor beta 2 (ERß2)- p53- FOXM1 signaling axis in high-grade serous ovarian cancer (HGSOC): Underlying mechanisms and implications for resistance to therapy. Clin. Cancer Res. 2018, 24, 111-112.

39. Domcke, S.; Sinha, R.; Levine, D.A.; Sander, C.; Schultz, N. Evaluating cell lines as tumour models by comparison of genomic profiles. Nat. Commun. 2013, 4, 2126. [CrossRef]

40. Contal, C.; O'Quigly, J. An application of changepoint methods in studying the effect of age on survival in breast cancer. Comput. Stat. Data Anal. 1999, 30, 253-270. [CrossRef]

41. Kyriakidis, I.; Papaioannidou, P. Estrogen receptor beta and ovarian cancer: A key to pathogenesis and response to therapy. Arch. Gynecol. Obstet. 2016, 293, 1161-1168. [CrossRef] [PubMed]

42. Ribeiro, J.R.; Freiman, R.N. Estrogen signaling crosstalk: Implications for endocrine resistance in ovarian cancer. J. Steroid Biochem. Mol. Biol. 2014, 143, 160-173. [CrossRef] [PubMed]

43. De Stefano, I.; Zannoni, G.F.; Prisco, M.G.; Fagotti, A.; Tortorella, L.; Vizzielli, G.; Mencaglia, L.; Scambia, G.; Gallo, D. Cytoplasmic expression of estrogen receptor beta (ERbeta) predicts poor clinical outcome in advanced serous ovarian cancer. Gynecol. Oncol. 2011, 122, 573-579. [CrossRef]

44. Mei, J.; Tian, H.; Huang, H.S.; Hsu, C.F.; Liou, Y.; Wu, N.; Zhang, W.; Chu, T.Y. Cellular models of development of ovarian high-grade serous carcinoma: A review of cell of origin and mechanisms of carcinogenesis. Cell Prolif. 2021, 54, e13029. [CrossRef] [PubMed]

45. Yemelyanova, A.; Vang, R.; Kshirsagar, M.; Lu, D.; Marks, M.A.; Shih Ie, M.; Kurman, R.J. Immunohistochemical staining patterns of p53 can serve as a surrogate marker for TP53 mutations in ovarian carcinoma: An immunohistochemical and nucleotide sequencing analysis. Mod. Pathol. 2011, 24, 1248-1253. [CrossRef] [PubMed]

46. Sandelin, A.; Alkema, W.; Engstrom, P.; Wasserman, W.W.; Lenhard, B. JASPAR: An open-access database for eukaryotic transcription factor binding profiles. Nucleic Acids Res. 2004, 32, D91-D94. [CrossRef]

47. Zona, S.; Bella, L.; Burton, M.J.; Nestal de Moraes, G.; Lam, E.W. FOXM1: An emerging master regulator of DNA damage response and genotoxic agent resistance. Biochim. Biophys. Acta 2014, 1839, 1316-1322. [CrossRef]

48. Bykov, V.J.; Issaeva, N.; Shilov, A.; Hultcrantz, M.; Pugacheva, E.; Chumakov, P.; Bergman, J.; Wiman, K.G.; Selivanova, G. Restoration of the tumor suppressor function to mutant p53 by a low-molecular-weight compound. Nat. Med. 2002, 8, 282-288. [CrossRef]

49. Mohell, N.; Alfredsson, J.; Fransson, A.; Uustalu, M.; Bystrom, S.; Gullbo, J.; Hallberg, A.; Bykov, V.J.; Bjorklund, U.; Wiman, K.G. APR-246 overcomes resistance to cisplatin and doxorubicin in ovarian cancer cells. Cell Death Dis. 2015, 6, e1794. [CrossRef]

50. Millour, J.; de Olano, N.; Horimoto, Y.; Monteiro, L.J.; Langer, J.K.; Aligue, R.; Hajji, N.; Lam, E.W. ATM and p53 regulate FOXM1 expression via E2F in breast cancer epirubicin treatment and resistance. Mol. Cancer Ther. 2011, 10, 1046-1058. [CrossRef]

51. Chang, E.C.; Frasor, J.; Komm, B.; Katzenellenbogen, B.S. Impact of Estrogen Receptor Beta on Gene Networks Regulated by Estrogen Receptor Alpha in Breast Cancer Cells. Endocrinology 2006, 147, 4831-4842. [CrossRef] [PubMed] 
52. Williams, C.; Edvardsson, K.; Lewandowski, S.A.; Strom, A.; Gustafsson, J.A. A genome-wide study of the repressive effects of estrogen receptor beta on estrogen receptor alpha signaling in breast cancer cells. Oncogene 2008, 27, 1019-1032. [CrossRef] [PubMed]

53. Blandino, G.; Di Agostino, S. New therapeutic strategies to treat human cancers expressing mutant p53 proteins. J. Exp. Clin. Cancer Res. 2018, 37, 30. [CrossRef]

54. Shafrir, A.L.; Babic, A.; Gates Kuliszewski, M.; Rice, M.S.; Townsend, M.K.; Hecht, J.L.; Tworoger, S.S. Estrogen Receptor-beta Expression of Ovarian Tumors and Its Association with Ovarian Cancer Risk Factors. Cancer Epidemiol. Biomark. Prev. 2020, 29, 2211-2219. [CrossRef] [PubMed] 